\title{
Strength enhancements in cold-formed structural sections - Part I: Material testing
}

\author{
S. Afshan ${ }^{(1)}$, B. Rossi ${ }^{(2)}$ and L. Gardner ${ }^{(3)}$ \\ ${ }^{(1),(3)}$ Imperial College London, London, UK, ${ }^{(2)}$ University of Liège, Liège, Belgium
}

\begin{abstract}
This paper describes a material test programme carried out as part of an extensive study into the prediction of strength enhancements in cold-formed structural sections. The experiments cover a wide range of cross-section geometries - twelve Square Hollow Sections (SHS), five Rectangular Hollow Sections (RHS) and one Circular Hollow Section (CHS), and materials austenitic (EN 1.4301, 1.4571 and 1.4404), ferritic (EN 1.4509 and 1.4003), duplex (EN 1.4462) and lean duplex (EN 1.4162) stainless steel and grade S355J2H carbon steel. The experimental techniques implemented, the generated data and the analysis methods employed are fully described. The results from the current test programme were combined with existing measured stress-strain data on cold-formed sections from the literature and following a consistent analysis of the combined data set, revised values for Young's modulus E and the Ramberg-Osgood material model parameters $\mathrm{n}, \mathrm{n}_{0.2, \mathrm{u}}^{\prime}$ and $\mathrm{n}_{0.2,1.0}^{\prime}$ are recommended. A comparison between the recommended values and the codified values provided in AS/NZS 4673 [1] , SEI/ASCE-8 [2] and EN 1993-1-4 [3] is also presented. The test results are also used in a companion paper [4] for developing suitable predictive models to determine the strength enhancements in cold-formed structural sections that arise during the manufacturing processes.
\end{abstract}

\section{Introduction}

Cold-formed structural sections are formed from sheet material which may be either hotrolled or cold-rolled, the latter being used for thinner gauges. The sheet material is typically rolled into coils for compact storage and transportation and is subsequently uncoiled prior to section forming. The processes of coiling and uncoiling of the sheet material and forming of the cross-section induce plastic deformations through the material thickness. Depending on the method of section forming employed - press-braking, where the sheet material is formed into the required shape by creating individual bends along its length, or cold-rolling, where gradual deformation of the uncoiled metal sheet through a series of successive rollers 
produces the final cross-section profile, different levels of plastic deformation are generated. The plastic deformations induced during the production processes influence the material response of the final cold-formed sections, with the key effects being an increase in yield strength, a reduction in ductility and the formation of residual stresses.

Predictive models for harnessing the increases in material strength caused by plastic deformations, experienced during the cold-forming production routes, have been developed for use in structural design. A comprehensive review of these models has been made in the companion paper [4], while a brief overview is presented herein.

Models for predicting the strength enhancement in the highly cold-worked corner regions of structural carbon steel cross-sections are provided in the following references: Karren [5], the AISI Specification for the Design of Cold-formed Steel Structural Members [6] and Gardner et al. [7]. A method for taking account of corner strength enhancements for cross-section design using an increased average yield strength is set out in EN 1993-1-3 [8].

For stainless steel, where the degree of non-linearity and the level of strain hardening are generally greater than carbon steel, separate predictive equations have been proposed. Experimental studies of cold-formed stainless steel sections were conducted by Coetzee et al. [9] and predictive equations were given by van den Berg and van der Merwe [10] for the corner regions of press-braked and cold-rolled sections. As part of their wider experimental study of the behaviour of austenitic stainless steels, Gardner and Nethercot [11] also developed an equation for predicting the increased $0.2 \%$ proof strength of the corner regions of cold-rolled box sections. Ashraf et al. [12] performed a comprehensive investigation into the behaviour of cold-formed stainless steel sections from a variety of fabrication processes and proposed a number of predictive models in terms of different material and geometric input parameters - allowing the wider applicability of the models. More recent predictive equations are provided in Cruise and Gardner [13] and Rossi [14], where the strength enhancement of the flat faces of cold-rolled sections has also been studied. In an attempt to provide a unified predictive method for all cold-worked non-linear metallic material, Rossi's [14] model involves the determination of the associated plastic strains caused during the fabrication process and evaluation of the corresponding stresses, through an appropriate material model. 
The present study builds on previous research and describes an experimental programme carried out to measure the level of strength enhancement in a wide range of cold-formed structural sections, covering both carbon steel and a variety of stainless steel grades. The programme consists of tensile tests on coupons extracted from a series of cold-rolled tubular sections, together with full section tensile tests. The majority of test programmes and proposed predictive models from the literature have focused on austenitic stainless steel sections, since, to date, this class of stainless steel has been the most commonly used in structural applications. Material properties of structural sections are often obtained as part of wider experimental research programmes by performing longitudinal tensile coupon tests; material test data on other stainless steel grades - duplex, lean duplex and ferritic, may therefore be sourced from published experiments in the literature. In order to develop a comprehensive experimental database, both in terms of the material grades and section geometries, the tested specimens for this research programme were selected to fill in the gaps in the existing available test data.

A wide range of cross-section geometries and material grades were considered. All tubular sections were formed by the cold-rolling process, whereby the sheet material was first formed into a circle and welded closed, followed by subsequent crushing into the final cross-section geometry for the case of SHS and RHS specimens. The experimental techniques implemented, the resulting data and the analysis methods employed throughout this experimental programme and discussion of the results are presented herein. A review of the compound Ramberg-Osgood material model is provided and revised values for the model parameters and the Young's modulus for a series of stainless steel grades are also proposed. The suitability of the expression recommended in Annex C of EN 1993-1-4 [3] for determining the strain at the ultimate tensile stress has also been assessed. In the companion paper [4], the test results from this experimental programme, combined with relevant test data from the literature, are analysed and used for appraisal of the existing predictive models and development of a simple, accurate and universal predictive model for harnessing the strength enhancements in cold-formed structural sections. 


\section{Experimental investigation}

\subsection{Cross-section geometries and grades}

A laboratory testing programme was conducted to investigate the influence of cold-working on the strength of cold-formed structural sections, and is described herein. A series of tensile coupon tests on material extracted from cold-formed tubular sections and full section tensile tests were performed. The section sizes and material grades of the tested specimens were selected to fill in the gaps in the existing literature test data. A total of eighteen cross-section geometries were considered including twelve Square Hollow Sections (SHS), five Rectangular Hollow Sections (RHS) and one Circular Hollow Section (CHS). A range of stainless steel grades - austenitic (EN 1.4301, 1.4571 and 1.4404), ferritic (EN 1.4509 and 1.4003), duplex (EN 1.4462) and lean duplex (EN 1.4162) - and one structural carbon steel grade $(\mathrm{S} 355 \mathrm{~J} 2 \mathrm{H})$ were included.

The chemical compositions and the tensile properties of the coil material from which the specimens were formed, as provided by the mill certificates, are presented in Tables 1 and 2, respectively. The notation employed in Table 2 is as follows: $\sigma_{0.2}$ is the $0.2 \%$ proof stress, $\sigma_{1.0}$ is the $1.0 \%$ proof stress, $\sigma_{u}$ is the ultimate tensile stress and $A_{5}$ is the elongation at fracture over a standard gauge length of $5.65 \sqrt{\mathrm{A}_{c}}$, where $\mathrm{A}_{\mathrm{c}}$ is the cross-sectional area of the coupon.

\subsection{Test specimens and measurements}

Two types of tensile coupons, flat coupons taken from the faces of the sections and corner coupons taken from the curved portions of the sections, in the longitudinal direction, were prepared. For all SHS and RHS specimens, two flat coupons taken from the centreline of the faces adjacent to the weld (labelled A1 and A2) and one flat coupon taken from the welded face (labelled S) were tested, resulting in a total of 51 flat coupons. In order to measure the extra strength enhancement associated with the formation of the highly cold-worked corner regions, two corner coupons were also extracted from the curved portions, opposite the welded face, of each of the cold-formed box sections, with the exception of the SHS $50 \times 50 \times 2$, SHS $40 \times 40 \times 2$ and SHS $30 \times 30 \times 2$ specimens where full section tensile tests were conducted. A total of 28 corner coupons (labelled C1 and C2) and 6 full sections - two specimens per section size - were prepared. Two coupons were also cut from the CHS 
$219.1 \times 8.2$ specimen. The locations of the flat and corner coupons in the tested cross-sections are shown in Fig. 1.

The coupons were dimensioned and tested in accordance with EN ISO 6892-1 [15]. All tensile flat coupons were necked - see Fig. 2(a). Based on the available machining facilities, a combination of straight coupons (Fig. 2(b)) and necked coupons, as illustrated in Fig. 2(c), were used for the corners. The straight corner coupons included the corner region plus an extension of $2 \mathrm{t}$, where $\mathrm{t}$ is the material thickness, beyond the corner radius into the flat faces of the section on either side.

Accurate measurements of the cross-section dimensions were taken. A digital Vernier calliper was used to measure the cross-section height $h$, width $b$ and thickness $t$, for each of the faces from which the coupons had been cut. Three measurements of the section width, height and face thickness were taken and averaged; the measurements are provided in Table 3 . Measurements of internal corner radius $r_{i}$ were made using an optical microscope and are also reported in Table 3. The measured geometric dimensions of the CHS specimen are also provided in Table 4 , where $\mathrm{R}_{\text {external }}$ and $\mathrm{R}_{\text {internal }}$ are the external and internal radii, respectively, and $\mathrm{t}$ is the section thickness, as illustrated in Fig.1.

In order to determine the cross-sectional area of the flat coupons, Vernier callipers was employed to obtain measurements of the width and the thickness of the coupon necked region. Three width measurements and three thickness measurements were taken along the coupon necked length and the cross-sectional area was determined as the product of the average width and thickness values. Owing to the adopted shapes of the corner coupons, the coupon cross-sectional area was less straightforward to calculate. The method used for calculating the cross sectional area of the corner coupons is outlined as follows: (1) the specimen's mass $M_{c}$ over a specified length $L_{c}$, marked on the coupon prior to testing, was measured after the test (2) the density @ of the cold-formed sections were obtained from the appropriate material specification, EN 10088-1 [16] for stainless steel sections and EN 10219-1 [17] for carbon steel sections (3) the cross-sectional area of the corner coupon specimen was calculated as Area $=\mathrm{M}_{\mathrm{c}} / \mathrm{L}_{\mathrm{c}} \mathrm{Q}$. A similar procedure was followed to determine the cross-sectional area of the full section specimens.

In order to measure the plastic strain at fracture, lines at $40 \mathrm{~mm}$ spacing were finely marked along the necked length of the necked coupons and along the full length of the straight 
coupons between the tensile test machine jaws with a scribe, as recommended by EN ISO 6892-1 [15]. Following the completion of the tensile coupon tests, the two halves of each of the coupons were fitted back together and the elongation after fracture was measured between scribe marks. If failure occurred in the grips of the tensile testing machine, strain at fracture was not measured. The measured values were used to calculate the percentage plastic strain at fracture using $\varepsilon_{\mathrm{pl}, \mathrm{f}}(\%)=\left[\left(\mathrm{L}_{\mathrm{u}}-\mathrm{L}_{0}\right) / \mathrm{L}_{0}\right] \times 100$, where $\mathrm{L}_{0}$ is the original marked length and $\mathrm{L}_{\mathrm{u}}$ is the extended length after fracture.

\subsection{Test set up and instrumentation}

All tensile coupon tests were performed using a Zwick/Roell Z100 kN electromechanical testing machine, in accordance with EN ISO 6892-1 [15], as illustrated in Fig. 3. A clip-on extensometer mounted directly onto the specimen was used to measure the longitudinal strain over a specified gauge length - see Fig. 4 (a). Two linear electrical resistance strain gauges attached to the edges of the A1 tensile coupons were also used to provide an additional measure of the strain - see Fig. 4 (b). The strain gauge readings were used to verify the accuracy of the extensometer measurements for the initial part of the stress-strain curves.

A selection of end-clamp configurations were used to allow appropriate gripping of the coupons in the tensile test machine jaws. A pair of flat surface clamps were used to grip the flat coupons at each end, while a combination of one flat and one v-shaped clamp were employed to hold the necked corner coupons. For some of the corner coupons, which were curved on both sides, a pair of v-shaped clamps were utilised and a steel rod was employed on the inner curved side of the coupon to fit into the v-shaped clamps - see Fig. 5. Load, strain and other relevant variables were all recorded at one second intervals using the ScanWin data acquisition system.

The SHS $50 \times 50 \times 2$ full section tensile tests were performed using a Zwick/Roell Z600 kN electromechanical testing machine while the SHS $40 \times 40 \times 2$ and SHS $30 \times 30 \times 2$ sections were tested in a Schenck RME $600 \mathrm{kN}$ electromechanical testing machine, in accordance with EN ISO 6892-1 [15]. The specimen ends were reinforced by fitting steel rods inside the specimens and were held in the machine jaws using flat end-clamps as illustrated in Figs. 6 (a) and (b). The instrumentation consisted of one linear variable displacement transducer (LVDT) to measure the elongation and a load cell to accurately record the applied load. All 
data, including load, displacement and other relevant variables were recorded at one second intervals using the ScanWin data acquisition system.

Strain control was used to drive the testing machine for the tensile coupon tests. According to the EN ISO 6892-1 [15] requirements, the strain rate should not exceed $0.25 \%$ strain/sec for the determination of the $0.2 \%$ proof strength, after which it may be increased to a maximum limit of $0.8 \%$ strain/sec. The adopted strain rates for the tensile coupon tests were $0.003 \%$ strain/sec up to $2.0 \%$ strain and $0.1 \%$ strain/sec until fracture. Displacement control was used to drive the testing machine for the full section tensile tests. According to the EN ISO 6892-1 [15] specification for tensile testing, the rate of separation of the cross-head of the tensile test machine should be such that the specimen remains within the specified stress limits of 6-60 $\mathrm{N} / \mathrm{mm}^{2} / \mathrm{sec}$ for material with Young's moduli above $150000 \mathrm{~N} / \mathrm{mm}^{2}$. The corresponding displacement rate range, with $\mathrm{E}=200000 \mathrm{~N} / \mathrm{mm}^{2}$ and a gauge length of $200 \mathrm{~mm}$, is 0.006 $0.06 \mathrm{~mm} / \mathrm{sec}$. A uniform cross-head displacement rate of $0.01 \mathrm{~mm} / \mathrm{sec}$ was used for all full section tensile tests.

\section{Experimental results and discussions}

\subsection{Introduction}

The results from the experiments described above are presented in this section. A review of the commonly adopted compound Ramberg-Osgood model, used for modelling the stressstrain response of non-linear materials, along with a robust curve fitting method for determining the model parameters, are provided. The results from the current test programme have been combined with existing measured stress-strain data on cold-formed stainless sections from the literature and revised values for the model parameters $\mathrm{n}, \mathrm{n}_{0.2, \mathrm{u}}^{\prime}$ and $\mathrm{n}_{0.2,1.0}^{\prime}$ and Young's modulus E for commonly used stainless steel grades are recommended. The expression for determining the strain at the ultimate tensile stress given in Annex C of EN 1993-1-4 [3] has also been investigated. A comparison between the recommended values from the present study and the codified values provided in AS/NZS 4673 [1], SEI/ASCE-8 [2] and EN 1993-1-4 [3] is also presented. Finally, the test results are used in a companion paper [4] for developing suitable predictive models to determine the strength enhancements in cold-formed structural sections that arise during the manufacturing process. 


\subsection{Tensile coupon tests}

A number of key material parameters were extracted from the recorded stress-strain curves for each tensile coupon. Firstly the best-fit Young's modulus was obtained based on the extensometer measurements. The $0.2 \%$ proof stress $\sigma_{0.2}, 1.0 \%$ proof stress $\sigma_{1.0}$, ultimate tensile stress $\sigma_{u}$, strain corresponding to the ultimate tensile stress $\varepsilon_{u}$, and plastic strain at fracture $\varepsilon_{\mathrm{pl}, \mathrm{f}}$, as described in Section 2.2, were determined. The test results for the flat coupons and the corner coupons are summarised in Tables 5 and 6, respectively. Typical measured stressstrain curves from austenitic, ferritic and duplex stainless steel are shown in Fig. 7.

\subsection{Full section tensile tests}

The results of the full section tensile tests for SHS $50 \times 50 \times 2$, SHS $40 \times 40 \times 2$ and SHS $30 \times 30 \times 2$ specimens are shown in Figs. 8-10. All test specimens failed by ductile fracture; Fig. 6 (c) shows typical failure modes. Key material properties including the best-fit Young's modulus, $0.2 \%$ proof stress $\sigma_{0.2}$, ultimate tensile stress $\sigma_{u}$ and the corresponding strain $\varepsilon_{\mathrm{u}}$ were determined for each section and are reported in Table 7 . The average $0.2 \%$ proof stress from the section tensile tests combined with the corresponding flat face material properties, from the tensile coupon test results, were used to infer the $0.2 \%$ proof stress of the sections' corner regions based on the proportion of the curved corner region cross-sectional area to the fullsection cross-sectional area; these values are also presented in Table 7.

\subsection{Compound Ramberg-Osgood material model}

Stainless steel displays highly non-linear stress-strain behaviour, with no sharply defined yield point, a significant amount of strain hardening and high ductility. In comparison, annealed carbon steel exhibits a linear elastic region, followed by a flat plastic plateau and a moderate degree of strain hardening. Cold-forming of such material leads to a more rounded stress-strain response, resembling that of stainless steel alloys. The familiar Ramberg-Osgood material model originally developed by Ramberg and Osgood [18] and later modified by Hill [19] has traditionally been used to replicate the behaviour of metallic materials with a nonlinear stress-strain response. The two stage Ramberg-Osgood material model developed by Mirambell and Real [20] and Rasmussen [21] - Eqs (1) and (2) - and that developed by Gardner and Nethercot [11] presented in its final form by Gardner and Ashraf [22] - Eqs (1) 
and (3) - have been utilised to replicate the measured stress-strain response of the tensile coupon tests presented in Section 3.2.

$$
\begin{aligned}
& \varepsilon=\frac{\sigma}{\mathrm{E}}+0.002\left(\frac{\sigma}{\sigma_{0.2}}\right)^{\mathrm{n}} \quad \text { for } \quad \sigma \leq \sigma_{0.2} \\
& \varepsilon=\frac{\sigma-\sigma_{0.2}}{\mathrm{E}_{0.2}}+\left(\varepsilon_{\mathrm{u}}-\varepsilon_{\mathrm{t}, 0.2}-\frac{\sigma_{\mathrm{u}}-\sigma_{0.2}}{\mathrm{E}_{0.2}}\right)\left(\frac{\sigma-\sigma_{0.2}}{\sigma_{\mathrm{u}}-\sigma_{0.2}}\right)^{\mathrm{n}_{0.2, \mathrm{u}}^{\prime}}+\varepsilon_{\mathrm{t}, 0.2} \quad \text { for } \quad \sigma_{0.2}<\sigma \leq \sigma_{\mathrm{u}} \\
& \varepsilon=\frac{\sigma-\sigma_{0.2}}{\mathrm{E}_{0.2}}+\left(\varepsilon_{\mathrm{t}, 1.0}-\varepsilon_{\mathrm{t}, 0.2}-\frac{\sigma_{1.0}-\sigma_{0.2}}{\mathrm{E}_{0.2}}\right)\left(\frac{\sigma-\sigma_{0.2}}{\sigma_{1.0}-\sigma_{0.2}}\right)^{\mathrm{n}_{0.2,1.0}^{\prime}}+\varepsilon_{\mathrm{t}, 0.2} \quad \text { for } \quad \sigma_{0.2}<\sigma \leq \sigma_{\mathrm{u}}
\end{aligned}
$$

The strain hardening exponent $\mathrm{n}$ is commonly determined based on two fixed points on the stress-strain curve. While the choice of the two fixed points is mainly dependent on the application of the model, one of these points is, by definition, taken as the $0.2 \%$ proof stress $\sigma_{0.2}$ with its corresponding total strain $\varepsilon_{\mathrm{t}, 0.2}$ while the $0.05 \%$ proof stress $\sigma_{0.05 \%}$ and its corresponding total strain $\varepsilon_{\mathrm{t}, 0.05}$ [20] or the $0.01 \%$ proof stress $\sigma_{0.01 \%}$ and its corresponding total strain $\varepsilon_{\mathrm{t}, 0.01}$ [21] have been commonly adopted as the second point. The strain hardening exponents $\mathrm{n}_{0.2, \mathrm{u}}^{\prime}$ and $\mathrm{n}_{0.2,1.0}^{\prime}$ may be evaluated from $\left(\sigma_{\mathrm{u}}, \varepsilon_{\mathrm{u}}\right)$ and $\left(\sigma_{1.0}, \varepsilon_{\mathrm{t}, 1.0}\right)$, respectively and another intermediate point, typically taken as the $0.5 \%$ proof stress $\sigma_{0.5 \%}$ and its corresponding total strain $\varepsilon_{\mathrm{t}, 0.5}$. Although determining the model parameters on the basis of distinct points along the measured stress-strain curve provides a relatively straightforward approach, the stress-strain description will be most accurate near the fixed points employed and inaccuracies may exist elsewhere. Hence, a method for accurately determining the model parameters based on a wider range of data points is necessary.

The ordinary least squares method, where the sum of the squares of the dependent variable is minimised, is commonly used for fitting equations to data points. Owing to the significant slope variation along the measured stress-strain curves, the residuals in the steeper region will have a greater influence on the fitting procedures than those in the flatter regions. Also, since the test rate is varied during the test, the data points are not evenly distributed along the stress-strain curve. As a result, more weighting will be given to the regions of the curve with high data concentration in the fitting procedures. Hence, a rigorous curve fitting approach has 
been employed herein for determining the best fit $\mathrm{n}, \mathrm{n}_{0.2, \mathrm{u}}^{\prime}$ and $\mathrm{n}_{0.2,1.0}^{\prime}$ values. The curve fitting method used involves a weighted total least squares regression which minimises the errors on both axes and is independent of the distribution of the data points. In order to remain unbiased toward any axis in the fitting procedures, the measured stress-strain data were normalised appropriately and weighting factors were employed to account for the nonuniform distribution of the data points along both axes, resulting in the objective function given by Eq. (4).

$$
\mathrm{S}=\operatorname{Min} \sum_{\mathrm{i}=1}^{\mathrm{i}=\mathrm{k}}\left(\mathrm{W}_{\varepsilon_{\mathrm{n}, \mathrm{i}}} \mathrm{r}_{\varepsilon_{\mathrm{n}, \mathrm{i}}}^{2}+\mathrm{W}_{\sigma_{\mathrm{n}, \mathrm{i}}} \mathrm{r}_{\sigma_{\mathrm{n}, \mathrm{i}}}^{2}\right)
$$

Where $r_{\varepsilon_{n, i}}$ is the residual in normalised $\varepsilon, r_{\sigma_{n, i}}$ is the residual in normalised $\sigma$ and $W_{\varepsilon_{n, i}}$ and $\mathrm{W}_{\sigma_{\mathrm{n}, \mathrm{i}}}$ are the weighting factors for normalised $\varepsilon$ and $\sigma$, respectively. The weighting factors are related to the interval between successive data points, where a large gap corresponds to a high weighting factor as defined by Eq. (5) and (6). Examples of the fitted curves to the experimental data are shown in Figs. 11 and 12.

$$
\begin{aligned}
& \mathrm{W}_{\varepsilon_{\mathrm{n}, \mathrm{i}}}=\left(\varepsilon_{\mathrm{n}, \mathrm{i}}-\varepsilon_{\mathrm{n}, \mathrm{i}-1}\right) \\
& \mathrm{W}_{\sigma_{\mathrm{n}, \mathrm{i}}}=\left(\sigma_{\mathrm{n}, \mathrm{i}}-\sigma_{\mathrm{n}, \mathrm{i}-1}\right)
\end{aligned}
$$

\subsection{Recommended compound Ramberg-Osgood model parameters $n, n_{0.2, u}^{\prime}$ and $n_{0.2,1.0}^{\prime}$}

The results from the current test programme have been combined with existing measured stress-strain data on cold-formed stainless steel sections from the literature and revised values for the model parameters $\mathrm{n}, \mathrm{n}_{0.2, \mathrm{u}}^{\prime}$ and $\mathrm{n}_{0.2,1.0}^{\prime}$ for commonly used stainless steel grades are recommended. Stress-strain data were sourced from Gardner [23] - 59 tensile and 53 compressive coupon tests on austenitic grade EN 1.4301, Nip et al. [24] - 8 tensile coupon tests on austenitic grade EN 1.4301, Theofanous and Gardner [25] - 16 tensile coupon tests on lean duplex grade EN 1.4162 and Afshan and Gardner [26] - 20 tensile and 16 compressive coupon tests on ferritic grades EN 1.4003 and EN 1.4509. All specimens were extracted from cold-formed tubular sections in the longitudinal direction. A summary of the obtained compound Ramberg-Osgood material model parameters is presented in Table 8. 
The European structural stainless steel design standard EN 1993-1-4 [3] provides two sets of $\mathrm{n}$ values for transverse and longitudinal loading directions. The values are recommended for both annealed and cold-formed material in tension and compression. In the Australian/New Zealand standard for cold-formed stainless steel structures AS/NZS 4673 [1], different $n$ values based on the loading direction, transverse and longitudinal, and loading type, tension and compression, are recommended for the design of cold-formed sections. The North American specification for the design of cold-formed stainless steel structural members SEI/ASCE 8-02 [2] provides a series of $\mathrm{n}$ values allowing for the loading type, loading direction and the material's level of cold-work. A summary of the codified $n$ values, covering the stainless steel grades considered in this study, for transverse tension and compression and longitudinal tension and compression are provided in Tables 9 and 10, respectively.

Table 11 compares the $\mathrm{n}$ parameters obtained in this study with their respective codified values. The recommended mean tensile $\mathrm{n}$ values for austenitic, ferritic and duplex stainless steel grades are also presented in Table 11. The $\mathrm{n}$ parameter is related to the degree of roundness of the stress-strain behaviour prior to the $0.2 \%$ proof stress and is expected to have a lower value for material with more rounded stress-strain behaviour. Analysis of the experimental results reflects the expected trend of having the lowest $n$ for the austenitic grades, which typically have the highest alloying content, the highest $\mathrm{n}$ for the ferritic grades and an intermediate $\mathrm{n}$ for the duplex grades.

\subsection{Strain at ultimate tensile stress}

Annex C of EN 1993-1-4 [3] for modelling the stress-strain response of stainless steels provides an expression for determining the strain at the ultimate tensile stress. This expression was developed by Rasmussen [21] on the basis of test data on austenitic, duplex and ferritic stainless steels. In developing this expression, Rasmussen [21] noted that it was not clear whether the ultimate tensile strain quoted in some references were the strain at the ultimate tensile strength, as had been assumed, or the strain at fracture including elongation from necking. Hence, the suitability of this expression has been further assessed herein based on measured strain data at the ultimate tensile stress. The results from a total of 93 tensile coupon tests from the present paper, Huang and Young [27] and Afshan and Gardner [26] were used. Fig. 13 compares the collected test data with the predictive model, and confirms the suitability of the proposal, with a mean test over predicted ratio of 0.99 and a COV of 
0.45, for the austenitic, duplex and lean duplex grades, but gives less accurate predictions for the ferritic grade.

\subsection{Stainless steel Young's modulus}

The slope of the linear elastic part of a uniaxial stress-strain curve is referred to as the material's Young's modulus. Young's moduli are typically obtained from tensile coupon tests, conducted in accordance with the relevant testing standards, such as the European standard EN ISO 6892-1 [15], American standard ASTM E8/E8M-11 [28] or Australian standard AS 1391 [29]. These standards are primarily concerned with measuring the full range stress-strain response of metallic materials and limited guidance on the accurate measurement of the Young's modulus is provided. Practical difficulties associated with a relatively short linear region at the beginning of the stress-strain curve also exist in the case of non-linear materials such as stainless steel.

A comprehensive review, covering the key practical issues associated with tensile testing and data analysis methods for the accurate determination of the Young's modulus, has been carried out by Roebuck et al. [30] and Lord and Morrell [31]. Method of strain measurement, misalignment and bending of the tensile coupon specimens as well as the data analysis technique employed, have been highlighted as having a potentially significant effect on the accuracy of the measured Young's modulus values. It was also reported that, double sided strain measurement systems such as high resolution double sided averaging extensometer or strain gauges attached to both sides of the tensile coupon specimen have been found to provide accurate strain measurements during the early important stage of the stress-strain curve used to calculate the Young's modulus. This point is fully supported based on the findings of the present study, and it is recommended that strain gauges attached to both sides of the coupons are employed, in order to achieve accurate measurements of Young's modulus particularly when curved coupons (due to the release of residual stresses) are being tested.

A concise and accurate method for the calculation of the Young's modulus from tensile stress-strain measurements has been developed as part of this study. Tensile coupon test results have been utilised to verify the method and propose appropriate Young's modulus values for a series of stainless steel grades. The method involves using an ordinary least squares regression analysis to fit a straight line through a suitable range of the test data in the 
initial part of the stress-strain curve following steps (1) to (7) below, with little or no operator intervention. The E values obtained are presented in Table 12.

(1) An initial value of the Young's modulus, taken as $200000 \mathrm{~N} / \mathrm{mm}^{2}$, for the first iteration, is assumed.

(2) The corresponding $0.2 \%$ proof stress $\sigma_{0.2}$ is defined.

(3) The secant modulus, defined as the slope of the line from the origin to the point on the stress-strain curve in consideration, is computed for each data point.

(4) A range of the stress-strain data is specified with the upper limit taken as $0.3 \sigma_{0.2}$ and the lower limit taken as the point where the ratio of the successive secant moduli is less than $80 \%$.

(5) A linear line is fitted through the data specified in step (4) using an ordinary least squares regression.

(6) The slope of the line is taken as the Young's modulus.

(7) Steps (1) to (6) are repeated until the Young's moduli values from Steps (6) and (1) are within $1 \%$.

Table 12 also compares the Young's modulus values obtained in this study with their respective codified values. The calculated values show good agreement with all the codified values except for the EN 1993-1-4 [3] high Young's modulus of $220000 \mathrm{~N} / \mathrm{mm}^{2}$ for the ferritic grades. It is recommended that an average value of $195000 \mathrm{~N} / \mathrm{mm}^{2}$ may be adopted for all stainless steel grades considered in this study, since no clear trend in measurements between grades is observed herein.

\section{Conclusions}

A material test programme on a total of eighteen cold-formed structural sections, including Square Hollow Sections (SHS), Rectangular Hollow Sections (RHS) and Circular Hollow Section (CHS) has been described. The results from tensile tests on 51 flat coupons, 28 corner coupons and 6 full section specimens have been presented. A review of the commonly adopted compound Ramberg-Osgood model, used for modelling the stress-strain response of non-linear materials, along with a robust curve fitting method for determining the model parameters have been provided. The results from the current test programme combined with existing measured stress-strain data on cold-formed stainless steel sections from the literature were used to propose revised values for the model parameters $\mathrm{n}, \mathrm{n}_{0.2, \mathrm{u}}^{\prime}$ and $\mathrm{n}_{0.2,1.0}^{\prime}$ and Young's 
modulus $\mathrm{E}$ for commonly used stainless steel grades. A comparison between the recommended values and the codified values provided in AS/NZS 4673 [1], SEI/ASCE-8 [2] and EN 1993-1-4 [3] was also presented. The obtained $n$ values were in accordance with the anticipated material response - having the lowest value for the austenitic grades, the highest value for the ferritic grades and an intermediate value for the duplex grades - which is not reflected in the current codified $\mathrm{n}$ values. It is recommended that a single Young's modulus value of $195000 \mathrm{~N} / \mathrm{mm}^{2}$ may be adopted for the stainless steel grades considered in this study. The suitability of the EN 1993-1-4 [3] Annex C expression for determining the strain at the ultimate tensile stress was also confirmed.

\section{Acknowledgements}

The authors are grateful to the Outokumpu Research Foundation, the Steel Construction Institute and the University of Liège for their financial and technical contributions to the project, and would like to thank the structures laboratory technicians at the University of Liège for their assistance in the experimental investigation and Pinelopi Kyvelou for her contribution to this research.

\section{References}

[1] AS/NZS 4673. Cold-formed stainless steel structures. Sydney: Standards Australia; 2001.

[2] SEI/ASCE 8-02. Specification for the design of cold-formed stainless steel structural members. Reston: American Society of Civil Engineers (ASCE); 2002.

[3] EN 1993-1-4. Eurocode 3: Design of steel structures - Part 1-4: General rules Supplementary rules for stainless steels. Brussels: European Committee for Standardization (CEN); 2006.

[4] Rossi B, Afshan S, Gardner L. Strength enhancements in cold-formed structural sections - Part II: Predictive models. Journal of Constructional Steel Research, 2013; 83:189-96.

[5] Karren K. Corner properties of cold-formed steel shapes. Journal of the Structural Division, ASCE, 1967;93(1):401-32.

[6] Specification for the design of cold-formed steel structural members. American Iron and Steel Institute (AISI); 1996. 
[7] Gardner L, Saari N, Wang F. Comparative experimental study of hot-rolled and coldformed rectangular hollow sections. Thin-walled structures, 2010;48(7):495-507.

[8] EN 1993-1-3. Eurocode 3: Design of steel structures - Part 1-3: General rules Supplementary rules for cold-formed members and sheeting. Brussels: European Committee for Standardization (CEN); 2006.

[9] Coetzee J, Van den Berg G, Van der Merwe P. The effect of work hardening and residual stresses due to cold-work of forming on the strength of cold-formed stainless steel lipped channel section. Tenth Intenational Speciality Conference on Cold-Formed Steel Structures. St. Louis, Missouri, USA, 1990. p. 143-62.

[10] Van den Berg G, Van der Merwe P. Prediction of corner mechanical properties for stainless steels due to cold forming. Eleventh International Speciality Conference on ColdFormed Steel Structures. St. Louise, Missouri, USA, 1992. p. 571-86.

[11] Gardner L, Nethercot D. Experiments on stainless steel hollow sections-Part 1: Material and cross-sectional behaviour. Journal of Constructional Steel Research, 2004;60(9):1291-318.

[12] Ashraf M, Gardner L, Nethercot D. Strength enhancement of the corner regions of stainless steel cross-sections. Journal of Constructional Steel Research, 2005;61(1):37-52.

[13] Cruise RB, Gardner L. Strength enhancements induced during cold forming of stainless steel sections. Journal of Constructional Steel Research, 2008;64(11):1310-6.

[14] Rossi B. Mechanical properties, residual stresses and structural behavior of thin-walled stainless steel profiles. PhD Thesis. Belgium: University of Liège; 2008.

[15] EN ISO 6892-1. Metallic materials - Tensile testing - Part 1: Method of test at room temperature. Brussels: European Committee for Standardization (CEN); 2009.

[16] EN 10088-1. Stainless steels - Part 1: List of stainless steels. Brussels: European Committee for Standardization (CEN); 2005. 
[17] EN 10219-1. Cold formed welded structural hollow sections of non-alloy and fine grain steels - Part 1: Technical delivery conditions. Brussels: European Committee for Standardization (CEN); 2006.

[18] Ramberg W, Osgood WR. Description of stress-strain curves by three parameters. 1943.

[19] Hill H. Determination of stress-strain relations from offset yield strength values. 1944.

[20] Mirambell E, Real E. On the calculation of deflections in structural stainless steel beams: an experimental and numerical investigation. Journal of Constructional Steel Research, 2000;54(1):109-33.

[21] Rasmussen KJR. Full-range stress-strain curves for stainless steel alloys. Journal of Constructional Steel Research, 2003;59(1):47-61.

[22] Ashraf M, Gardner L, Nethercot DA. Finite element modelling of structural stainless steel cross-sections. Thin-walled structures, 2006;44(10):1048-62.

[23] Gardner L. A new approach to structural stainless steel design. PhD Thesis. UK: Imperial College London; 2002.

[24] Nip K, Gardner L, Elghazouli A. Cyclic testing and numerical modelling of carbon steel and stainless steel tubular bracing members. Engineering Structures, 2010;32(2):424-41.

[25] Theofanous M, Gardner L. Experimental and numerical studies of lean duplex stainless steel beams. Journal of Constructional Steel Research, 2010;66(6):816-25.

[26] Afshan S, Gardner L. Experimental study of cold-formed ferritic stainless steel hollow sections. Journal of Structural Engineering (ASCE), In press.

[27] Huang Y, Young B. Material properties of cold-formed lean duplex stainless steel sections. Thin-walled structures, 2012;54:72-81.

[28] ASTM Standard E8/E8M. Standard Test Methods for Tension Testing of Metallic Materials. West Conshohocken: ASTM International; 2011. 
[29] AS 1391. Metallic materials - Tensile testing at ambient temperature. Sydney: Standards Australia; 2007.

[30] Roebuck B, Lord J, Cooper P, McCartney L. Data acquisition and analysis of tensile properties for metal matrix composites. Journal of Testing and Evaluation, 1994;22(1):63-9.

[31] Lord J, Morrell R. Elastic modulus measurement-obtaining reliable data from the tensile test. Metrologia, 2010;47(2):S41. 

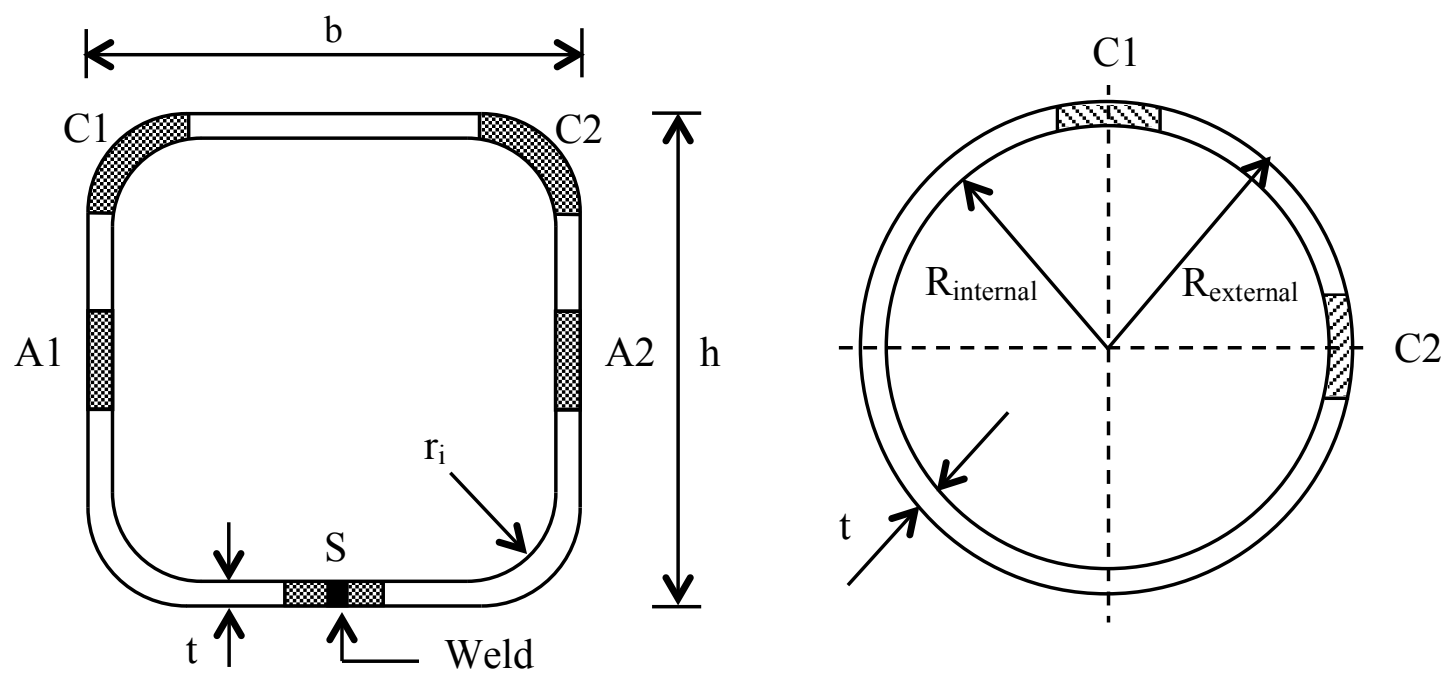

Fig. 1. Definition of symbols and locations of coupons in the cross-section.

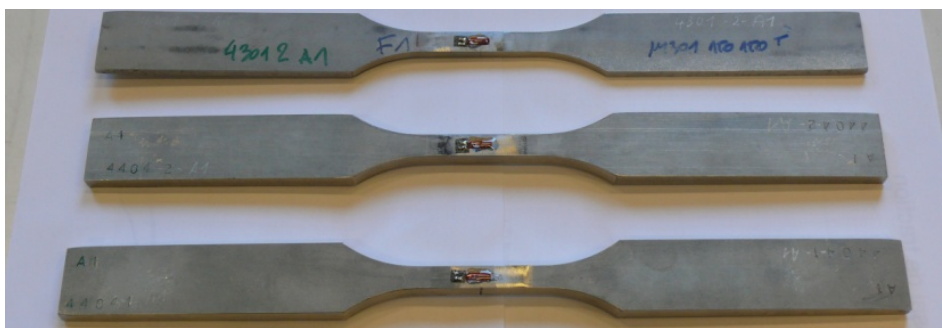

(a) Necked flat coupons.

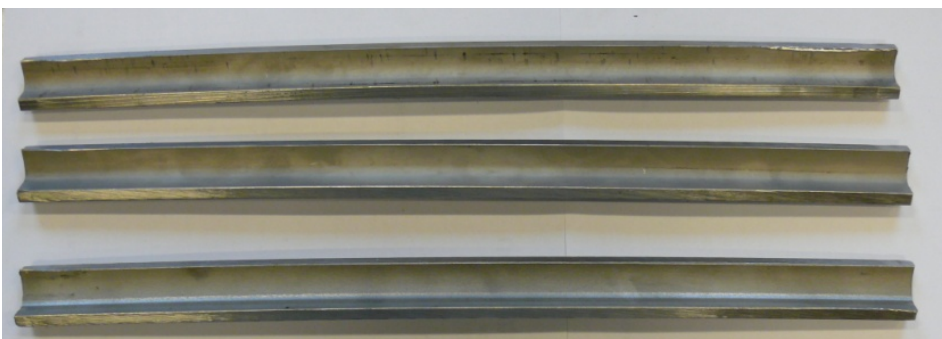

(b) Straight corner coupons.

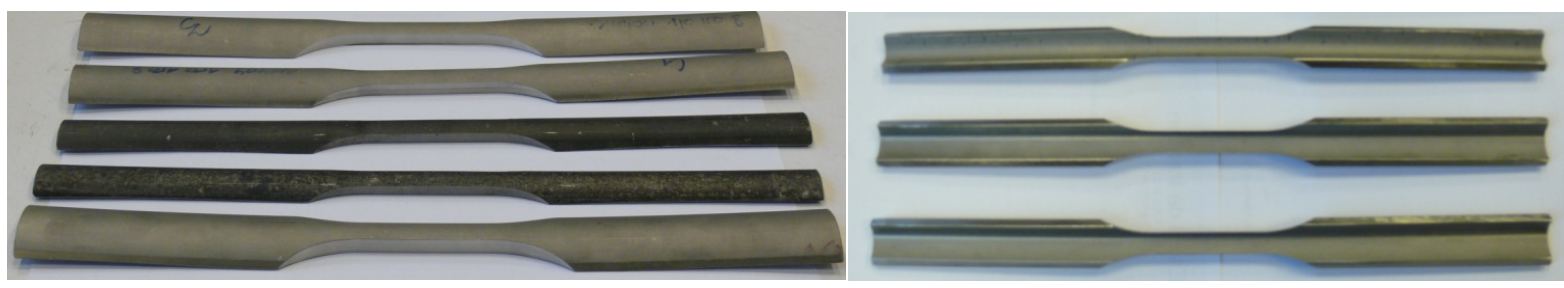

(c) Necked corner coupons.

Fig 2. Tensile coupon specimens. 


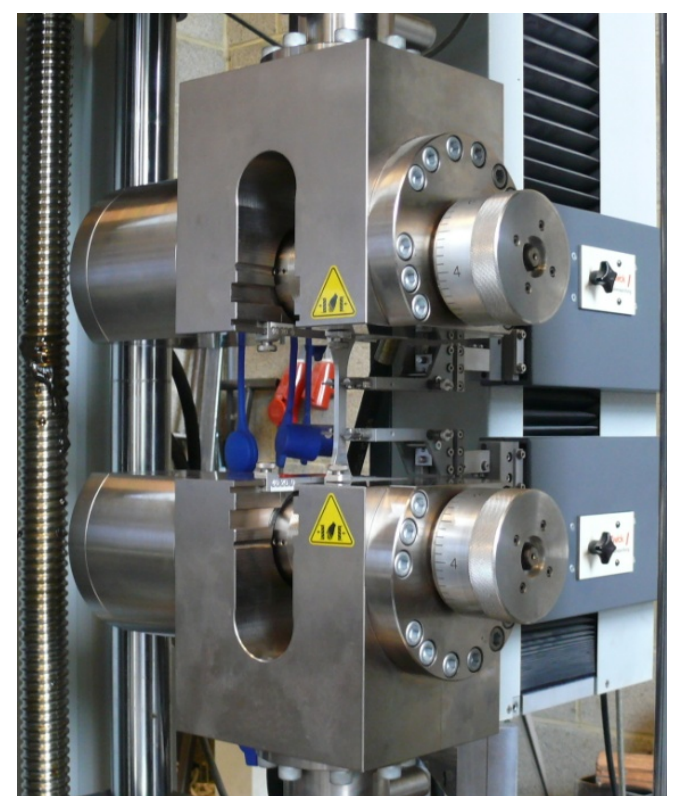

Fig. 3. Tensile coupon test set-up.

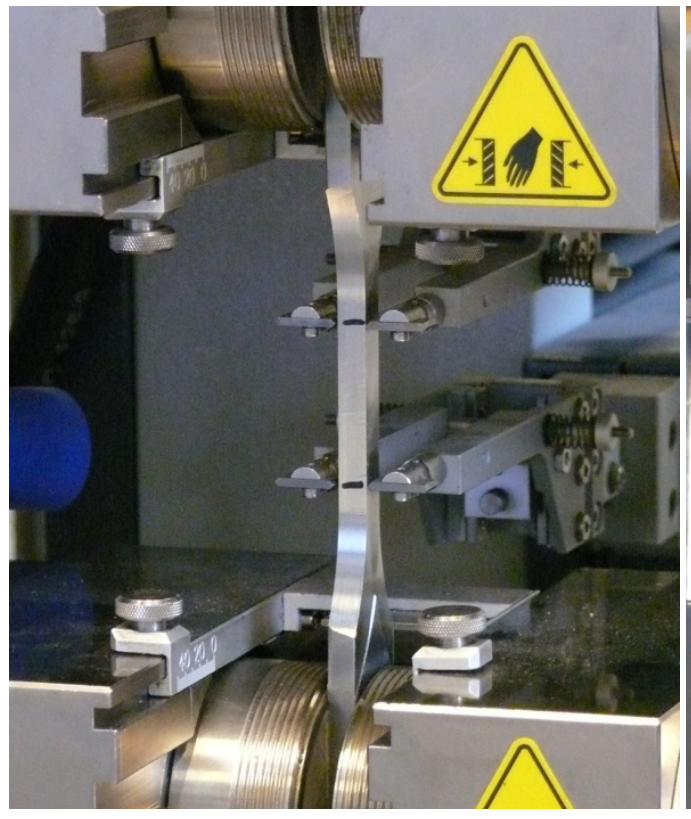

(a) Clip-on extensometer.

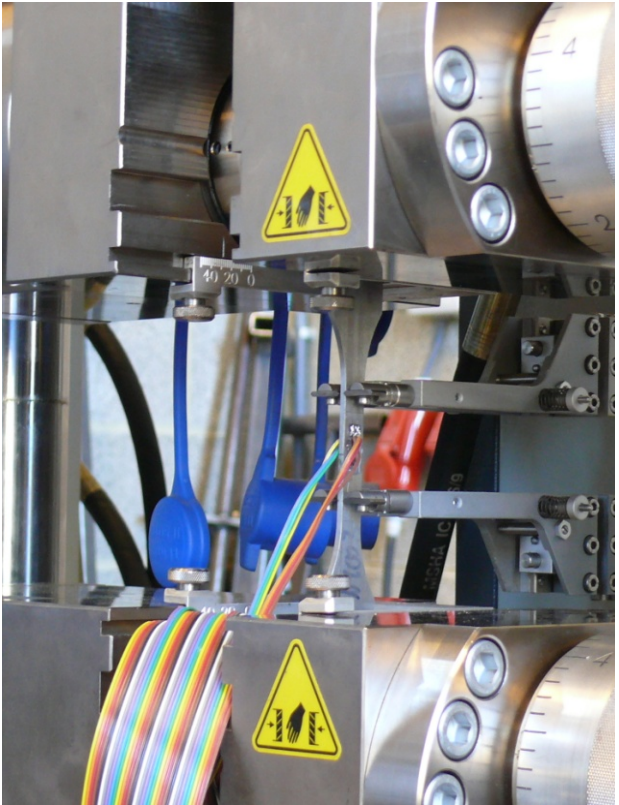

(b) Electrical resistance strain gauges.

Fig. 4. Tensile coupon test strain measurement techniques. 


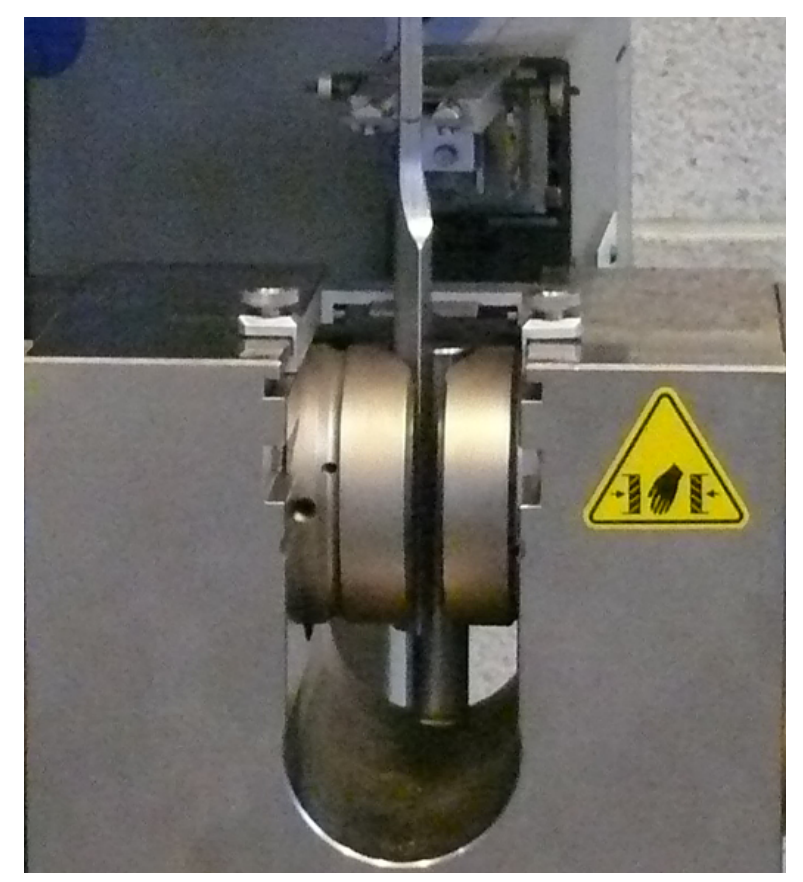

Fig. 5. End-clamp configuration of the curved corner coupons.

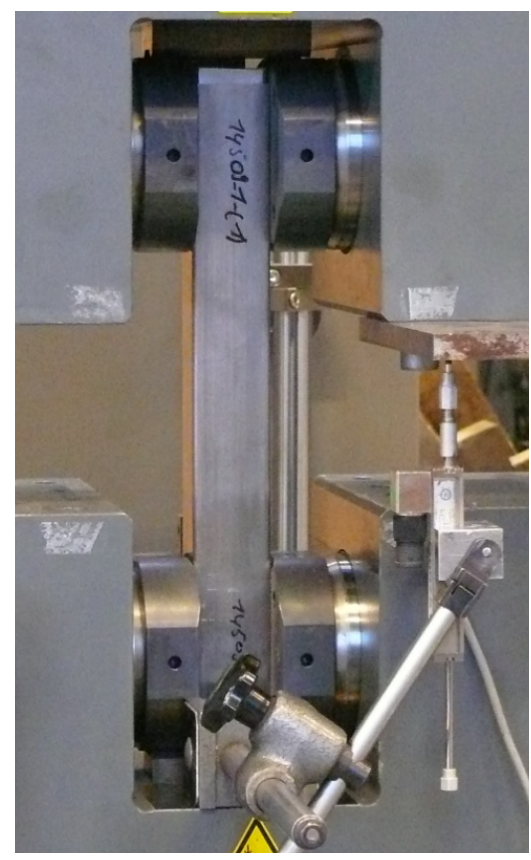

(a) Test set-up

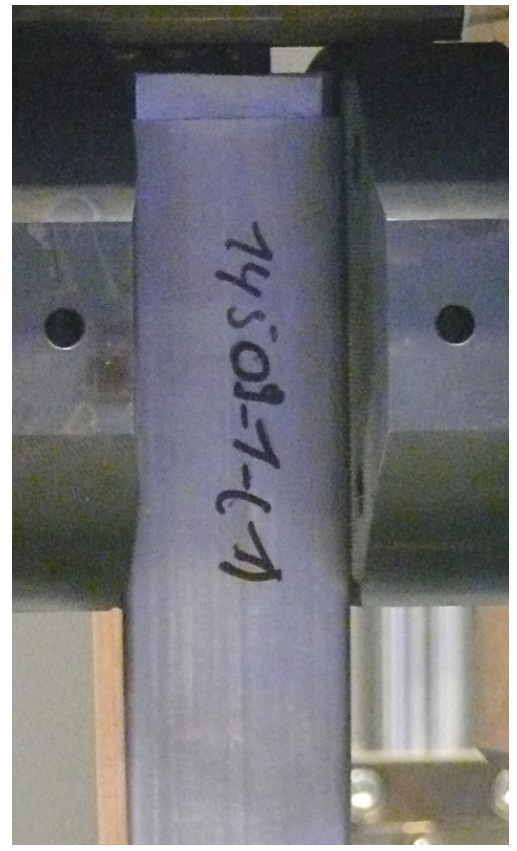

(b) End-clamp configuration

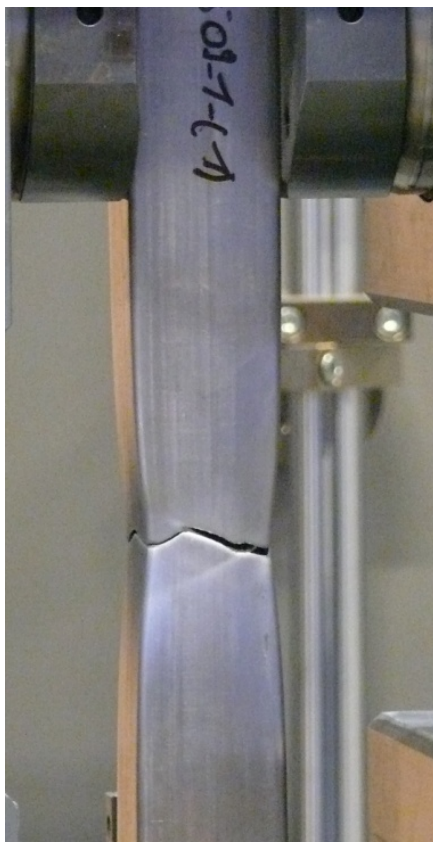

(c) Typical failure mode

Fig. 6. Full section tensile tests. 


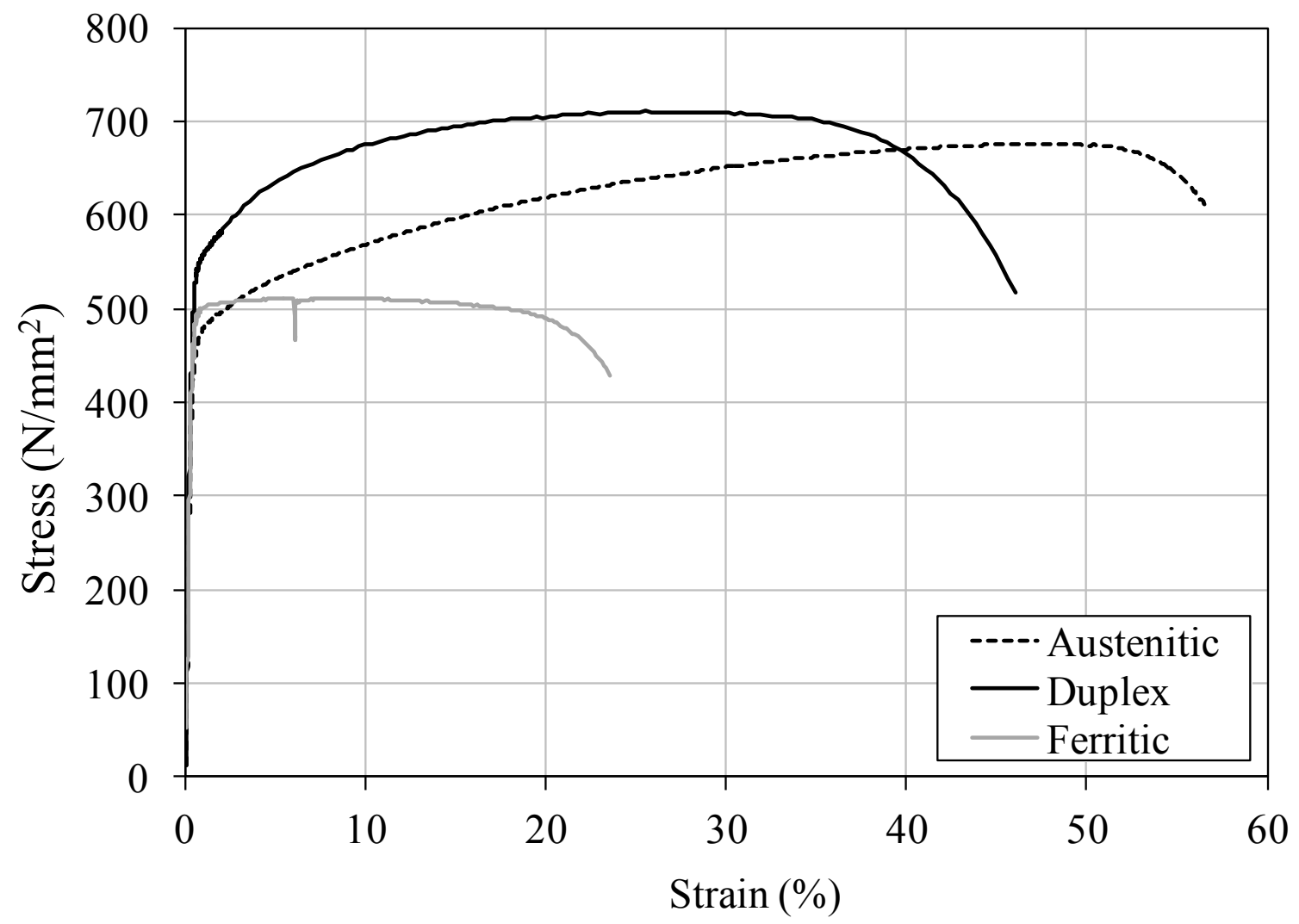

Fig. 7. Typical stress-strain curves for austenitic, ferritic and duplex stainless steel grades. 


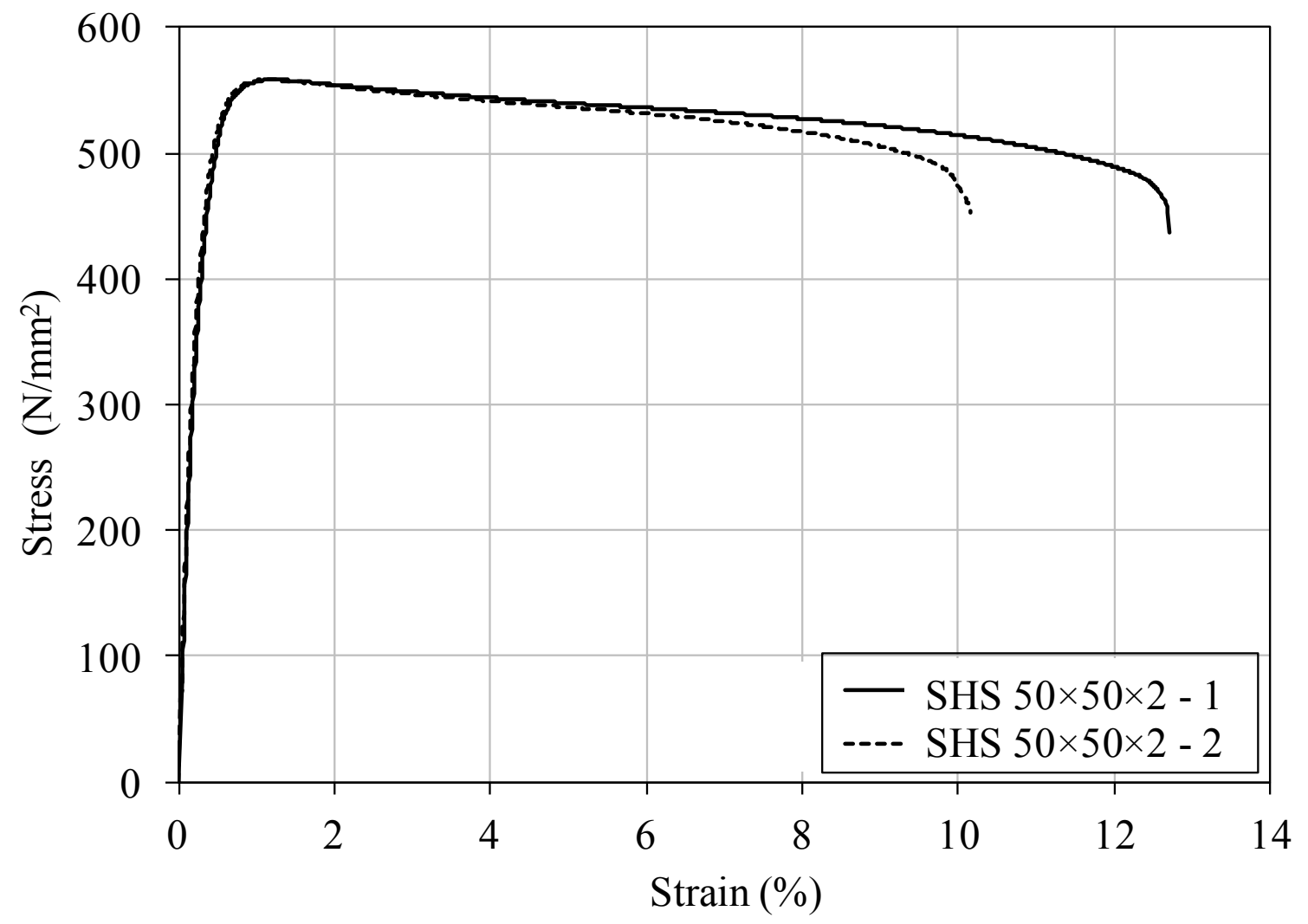

Fig. 8. Tensile stress-strain curves for $50 \times 50 \times 2$ sections. 


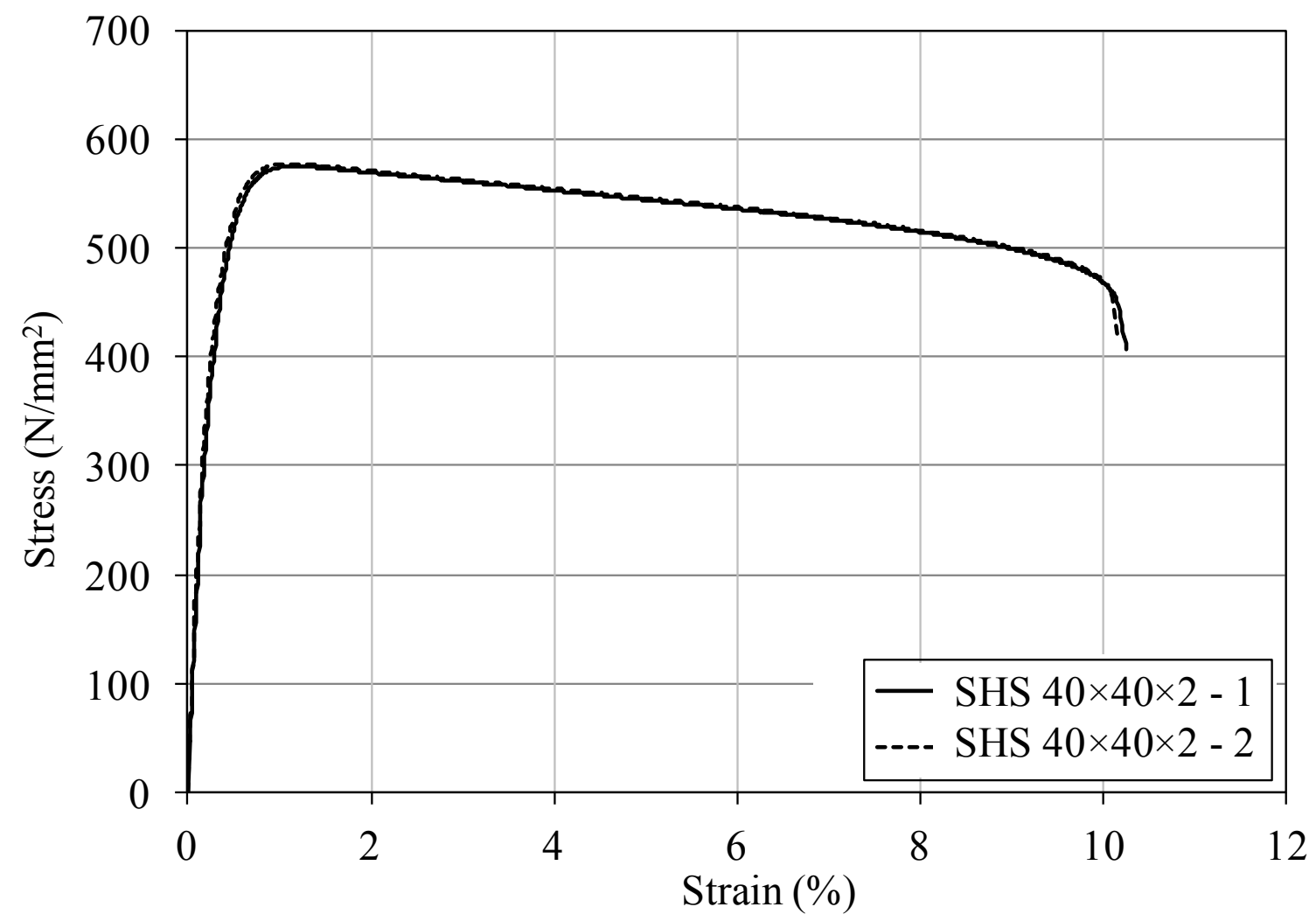

Fig. 9. Tensile stress-strain curves for $40 \times 40 \times 2$ sections. 


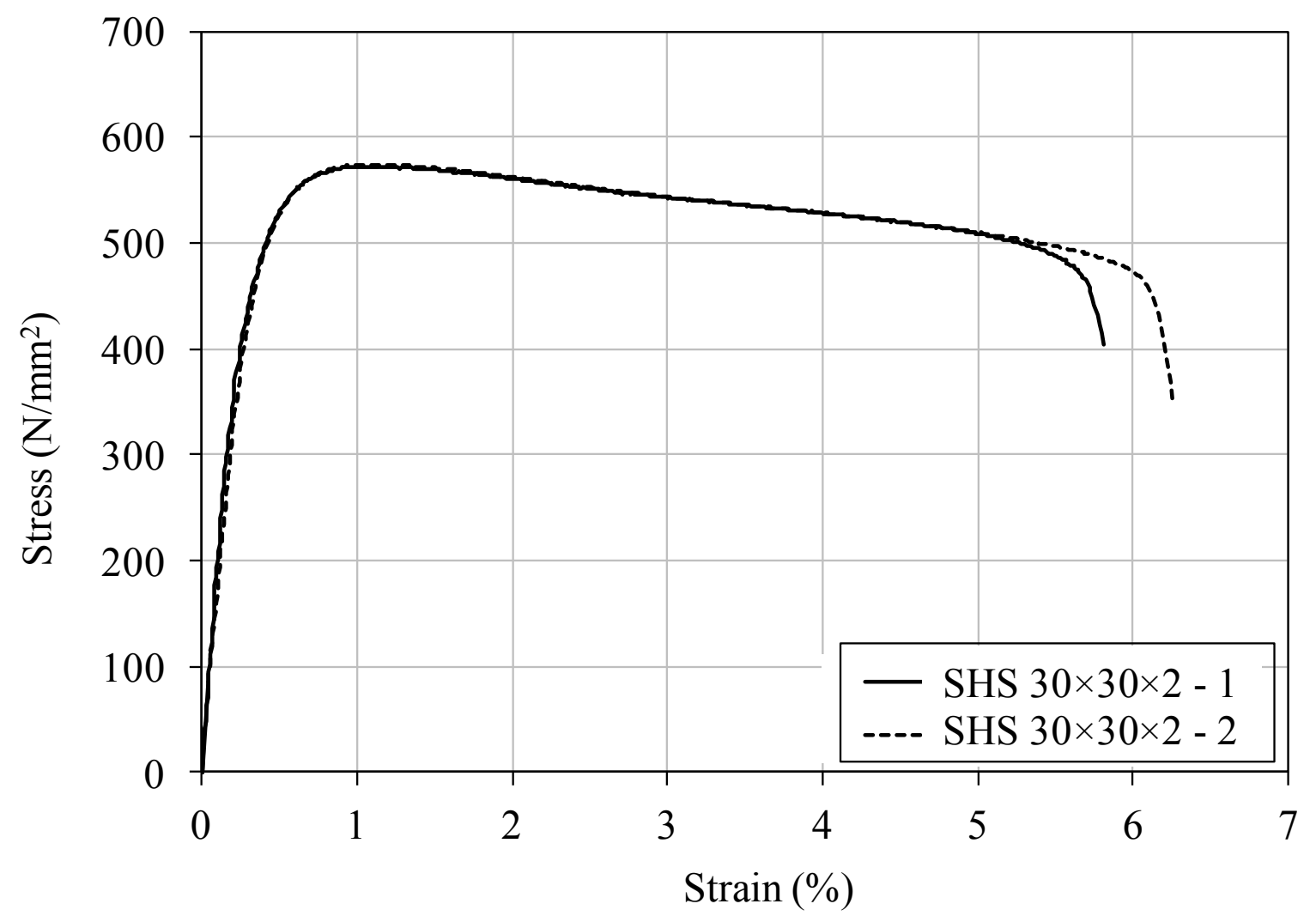

Fig. 10. Tensile stress-strain curves for $30 \times 30 \times 2$ sections. 


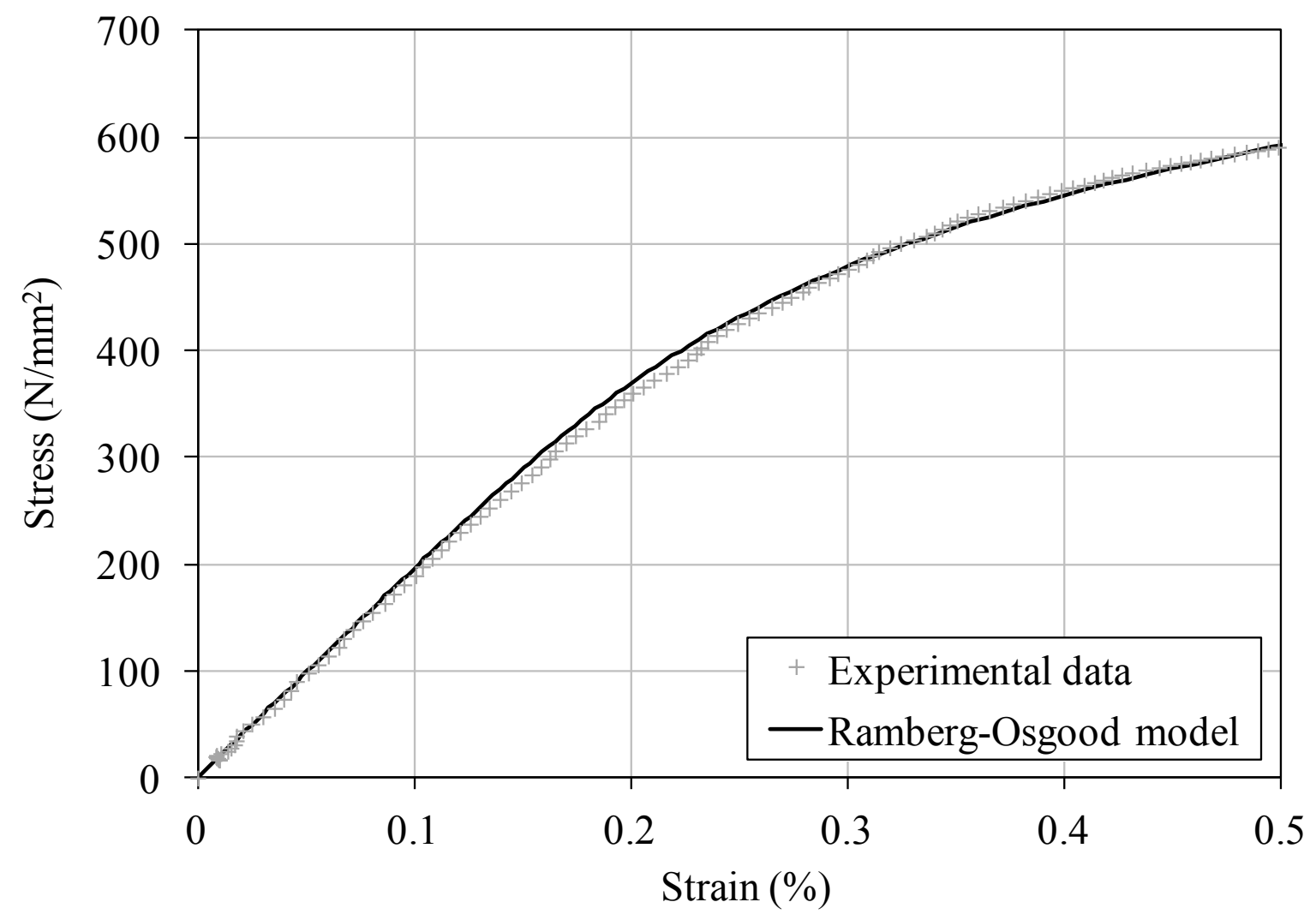

Fig. 11. Best fit curve of Eq.(1) to experimental data. 


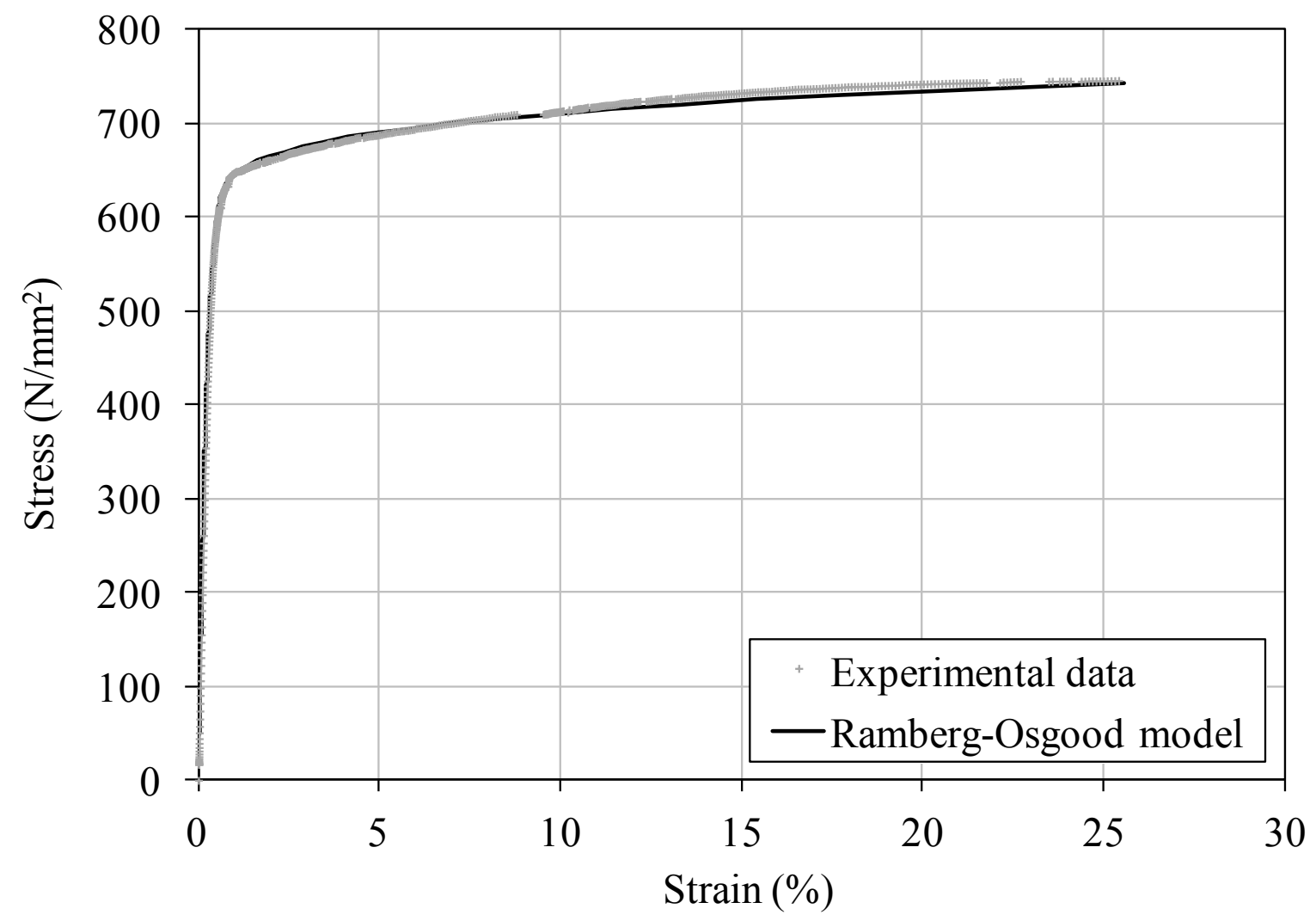

Fig. 12. Best fit curve of Eq.( 2) to experimental data. 


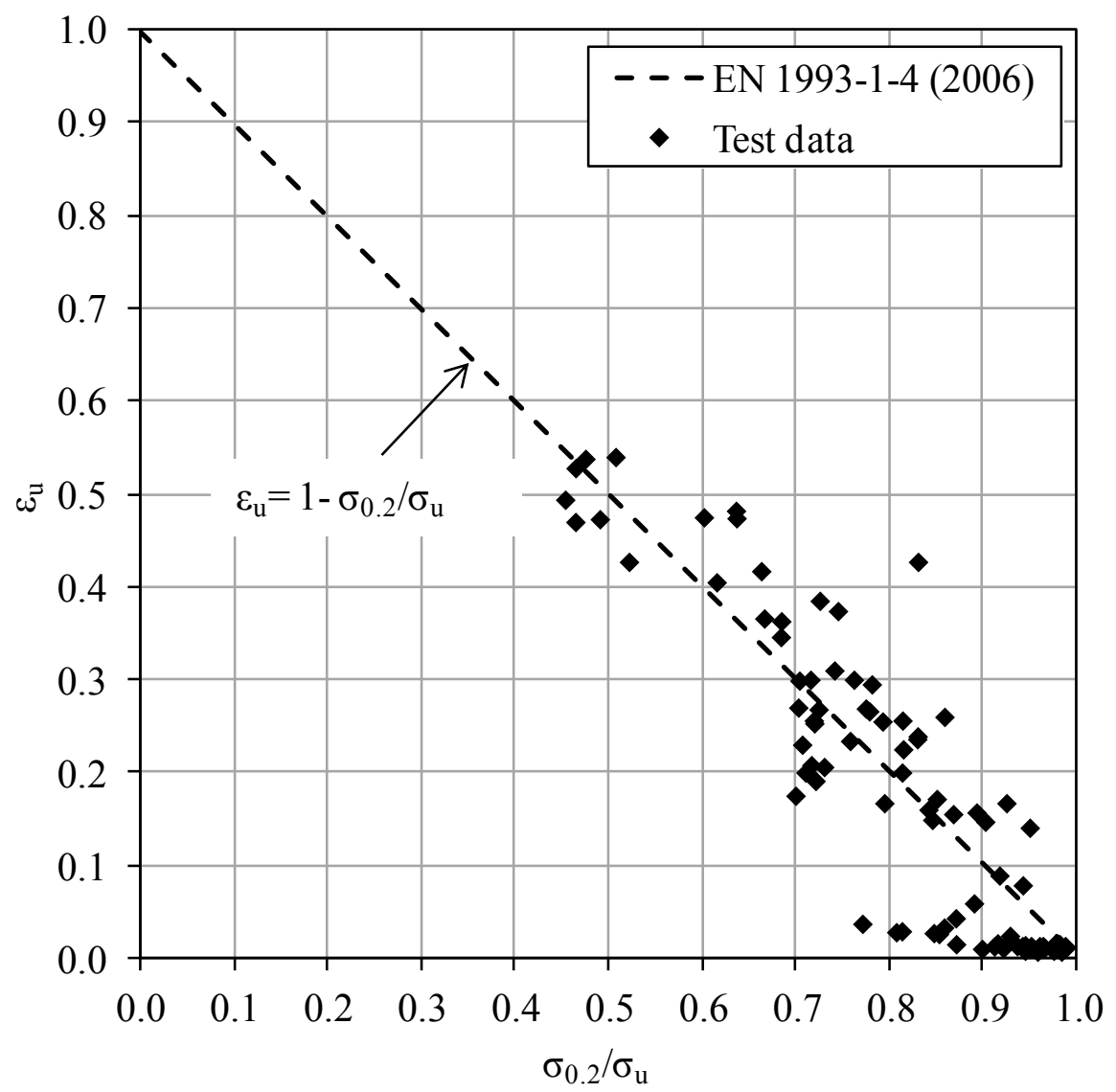

Fig. 13. Prediction of the strain at the ultimate tensile stress. 
Table 1. Chemical compositions as stated in the mill certificates

\begin{tabular}{|c|c|c|c|c|c|c|c|c|c|c|c|c|}
\hline Cross-section & $\begin{array}{l}\text { Material } \\
\text { grade }\end{array}$ & $\begin{array}{c}\mathrm{C} \\
(\%)\end{array}$ & $\begin{array}{l}\mathrm{Si} \\
(\%)\end{array}$ & $\begin{array}{l}\mathrm{Mn} \\
(\%)\end{array}$ & $\begin{array}{c}\mathrm{P} \\
(\%)\end{array}$ & $\begin{array}{c}\mathrm{S} \\
(\%)\end{array}$ & $\begin{array}{l}\mathrm{Cr} \\
(\%)\end{array}$ & $\begin{array}{l}\mathrm{Ni} \\
(\%)\end{array}$ & $\begin{array}{l}\mathrm{N} \\
(\%)\end{array}$ & $\begin{array}{l}\text { Mo } \\
(\%)\end{array}$ & $\begin{array}{l}\mathrm{Cu} \\
(\%)\end{array}$ & $\begin{array}{l}\mathrm{Nb} \\
(\%)\end{array}$ \\
\hline SHS $100 \times 100 \times 5$ & 1.4301 & 0.044 & 0.350 & 1.34 & 0.029 & 0.001 & 18.24 & 8.12 & 0.058 & 0.210 & - & - \\
\hline SHS $150 \times 150 \times 5$ & $1.4301 / 1.430$ & 0.022 & 0.390 & 1.80 & 0.030 & 0.001 & 18.20 & 8.00 & 0.050 & - & - & - \\
\hline RHS $150 \times 100 \times 6$ & $1.4301 / 1.430$ & 0.023 & 0.390 & 1.76 & 0.029 & 0.001 & 18.20 & 8.10 & 0.043 & - & - & - \\
\hline SHS $100 \times 100 \times 5$ & 1.4571 & 0.010 & 0.400 & 1.79 & 0.033 & 0.001 & 16.60 & 10.70 & 0.010 & 2.070 & - & - \\
\hline SHS $120 \times 120 \times 5$ & 1.4571 & 0.040 & 0.390 & 1.22 & 0.027 & 0.001 & 16.70 & 10.70 & 0.010 & 2.060 & - & - \\
\hline SHS $150 \times 150 \times 8$ & 1.4404 & 0.025 & 0.530 & 1.75 & 0.030 & 0.000 & 17.20 & 10.10 & 0.044 & 2.090 & - & - \\
\hline RHS $150 \times 100 \times 8$ & 1.4404 & 0.022 & 0.490 & 1.74 & 0.032 & 0.002 & 17.00 & 10.00 & 0.042 & 2.040 & - & - \\
\hline SHS $50 \times 50 \times 2$ & 1.4509 & 0.013 & 0.430 & 0.22 & 0.021 & 0.001 & 18.26 & 0.19 & 0.013 & 0.020 & - & 0.38 \\
\hline SHS $40 \times 40 \times 2$ & 1.4509 & 0.015 & 0.550 & 0.20 & 0.024 & 0.001 & 18.27 & 0.20 & 0.016 & 0.020 & - & 0.36 \\
\hline SHS $30 \times 30 \times 2$ & 1.4509 & 0.015 & 0.560 & 0.20 & 0.024 & 0.001 & 18.27 & 0.20 & 0.016 & 0.020 & - & 0.36 \\
\hline RHS $120 \times 80 \times 3$ & 1.4003 & 0.010 & 0.250 & 1.43 & 0.028 & 0.003 & 11.30 & 0.40 & 0.010 & - & - & - \\
\hline SHS $80 \times 80 \times 3$ & 1.4003 & 0.007 & 0.230 & 1.39 & 0.025 & 0.002 & 11.20 & 0.40 & 0.010 & - & - & - \\
\hline SHS $150 \times 150 \times 8$ & 1.4162 & 0.029 & 0.740 & 4.97 & 0.020 & 0.001 & 21.68 & 1.59 & 0.215 & 0.320 & 0.34 & - \\
\hline CHS $219.1 \times 8.2$ & 1.4462 & 0.016 & 0.450 & 1.66 & 0.025 & 0.001 & 22.38 & 5.35 & 0.190 & 3.070 & - & - \\
\hline SHS $150 \times 150 \times 6$ & $\mathrm{~S} 355 \mathrm{~J} 2 \mathrm{H}$ & 0.200 & 0.017 & 1.48 & 0.009 & 0.008 & 0.016 & 0.018 & 0.007 & 0.002 & 0.036 & 0.033 \\
\hline RHS $200 \times 100 \times 5$ & $\mathrm{~S} 355 \mathrm{~J} 2 \mathrm{H}$ & 0.130 & 0.017 & 1.40 & 0.015 & 0.003 & 0.030 & 0.010 & 0.006 & 0.010 & 0.010 & 0.034 \\
\hline RHS $150 \times 100 \times 6$ & $\mathrm{~S} 355 \mathrm{~J} 2 \mathrm{H}$ & 0.143 & 0.176 & 0.92 & 0.009 & 0.006 & 0.024 & 0.047 & - & 0.002 & 0.028 & - \\
\hline SHS $200 \times 200 \times 6$ & $\mathrm{~S} 355 \mathrm{~J} 2 \mathrm{H}$ & 0.155 & 0.216 & 1.05 & 0.013 & 0.007 & 0.022 & 0.019 & 0.005 & 0.008 & 0.035 & 0.002 \\
\hline
\end{tabular}

Table 2. Mechanical properties as stated in the mill certificates

\begin{tabular}{|c|c|c|c|c|c|}
\hline Cross-section & $\begin{array}{l}\text { Material } \\
\text { grade }\end{array}$ & $\begin{array}{c}\sigma_{0.2, \text { mill }} \\
\left(\mathrm{N} / \mathrm{mm}^{2}\right)\end{array}$ & $\begin{array}{c}\sigma_{1.0, \text { mill }} \\
\left(\mathrm{N} / \mathrm{mm}^{2}\right)\end{array}$ & $\begin{array}{c}\sigma_{u, \text { mill }} \\
\left(\mathrm{N} / \mathrm{mm}^{2}\right)\end{array}$ & $\begin{array}{l}\mathrm{A}_{5} \\
(\%)\end{array}$ \\
\hline SHS $100 \times 100 \times 5$ & 1.4301 & 310 & $-(1)$ & 670 & 51 \\
\hline SHS $150 \times 150 \times 5$ & $1.4301 / 1.4307$ & 289 & 342 & 621 & 53 \\
\hline RHS $150 \times 100 \times 6$ & $1.4301 / 1.4307$ & 284 & 328 & 603 & 56 \\
\hline SHS $100 \times 100 \times 5$ & 1.4571 & 272 & 312 & 562 & 60 \\
\hline SHS $120 \times 120 \times 5$ & 1.4571 & 268 & 315 & 584 & 53 \\
\hline SHS $150 \times 150 \times 8$ & 1.4404 & 302 & 358 & 605 & 51 \\
\hline RHS $150 \times 100 \times 8$ & 1.4404 & 285 & 336 & 590 & 53 \\
\hline SHS $50 \times 50 \times 2$ & 1.4509 & 364 & $-{ }^{(1)}$ & 501 & 30 \\
\hline SHS $40 \times 40 \times 2$ & 1.4509 & 362 & $-^{(1)}$ & 476 & 33 \\
\hline SHS $30 \times 30 \times 2$ & 1.4509 & 362 & $-^{(1)}$ & 476 & 33 \\
\hline RHS $120 \times 80 \times 3$ & 1.4003 & 329 & 350 & 468 & 37 \\
\hline SHS $80 \times 80 \times 3$ & 1.4003 & 324 & 342 & 467 & 45 \\
\hline SHS $150 \times 150 \times 8$ & 1.4162 & 561 & 605 & 747 & $-^{(1)}$ \\
\hline CHS $219.1 \times 8.2$ & 1.4462 & 650 & $-(1)$ & 819 & 33 \\
\hline SHS $150 \times 150 \times 6$ & $\mathrm{~S} 355 \mathrm{~J} 2 \mathrm{H}$ & 420 & $-(1)$ & 529 & 31 \\
\hline RHS $200 \times 100 \times 5$ & $\mathrm{~S} 355 \mathrm{~J} 2 \mathrm{H}$ & 478 & $-^{(1)}$ & 546 & 27 \\
\hline RHS $150 \times 100 \times 6$ & $\mathrm{~S} 355 \mathrm{~J} 2 \mathrm{H}$ & 384 & $-^{(1)}$ & 511 & 24 \\
\hline SHS $200 \times 200 \times 6$ & $\mathrm{~S} 355 \mathrm{~J} 2 \mathrm{H}$ & 475 & $-^{(1)}$ & 549 & $-^{(1)}$ \\
\hline
\end{tabular}

Note:

-1) Values were not provided 
Table 3. Average measured dimensions of the SHS and RHS specimens

\begin{tabular}{|c|c|c|c|c|c|c|c|c|}
\hline \multirow[t]{2}{*}{ Cross-section } & \multirow{2}{*}{$\begin{array}{l}\text { Material } \\
\text { grade }\end{array}$} & \multirow{2}{*}{$\begin{array}{c}\mathrm{h} \\
(\mathrm{mm})\end{array}$} & \multirow{2}{*}{$\begin{array}{c}\mathrm{b} \\
(\mathrm{mm})\end{array}$} & \multicolumn{3}{|c|}{$\mathrm{t}(\mathrm{mm})$} & \multicolumn{2}{|c|}{$\mathrm{r}_{\mathrm{i}}(\mathrm{mm})$} \\
\hline & & & & $\mathrm{A} 1$ & A2 & $\mathrm{S}$ & $\mathrm{C} 1$ & $\mathrm{C} 2$ \\
\hline SHS $100 \times 100 \times 5$ & 1.4301 & 99.99 & 99.85 & 4.65 & 4.67 & 4.62 & 2.38 & 1.78 \\
\hline SHS $150 \times 150 \times 5$ & $1.4301 / 1.4307$ & 149.82 & 149.88 & 4.99 & 5.02 & 4.99 & 5.94 & 7.42 \\
\hline RHS $150 \times 100 \times 6$ & $1.4301 / 1.4307$ & 150.57 & 100.03 & 5.89 & 5.86 & 5.87 & 7.42 & 6.68 \\
\hline SHS $100 \times 100 \times 5$ & 1.4571 & 100.09 & 99.73 & 4.69 & 4.68 & 4.71 & 5.05 & 5.94 \\
\hline SHS $120 \times 120 \times 5$ & 1.4571 & 120.30 & 120.14 & 4.63 & 4.67 & 4.62 & 5.64 & 5.94 \\
\hline SHS $150 \times 150 \times 8$ & 1.4404 & 150.01 & 150.51 & 7.77 & 7.76 & 7.76 & 9.65 & 11.13 \\
\hline RHS $150 \times 100 \times 8$ & 1.4404 & 150.01 & 100.20 & 7.78 & 7.73 & 7.73 & 8.91 & 10.39 \\
\hline SHS $50 \times 50 \times 2$ & 1.4509 & 50.14 & 50.26 & 1.89 & 1.91 & 1.89 & 2.50 & 2.50 \\
\hline SHS $40 \times 40 \times 2$ & 1.4509 & 40.07 & 40.02 & 2.02 & 2.03 & 2.00 & 1.75 & 1.75 \\
\hline SHS $30 \times 30 \times 2$ & 1.4509 & 29.98 & 29.97 & 1.90 & 1.95 & 1.95 & 1.50 & 1.50 \\
\hline RHS $120 \times 80 \times 3$ & 1.4003 & 119.84 & 79.67 & 2.81 & 2.83 & 2.81 & 3.86 & 4.16 \\
\hline SHS $80 \times 80 \times 3$ & 1.4003 & 79.75 & 79.74 & 2.81 & 2.80 & 2.79 & 3.56 & 4.16 \\
\hline SHS $150 \times 150 \times 8$ & 1.4162 & 150.42 & 150.02 & 8.01 & 8.05 & 8.05 & 11.17 & 11.16 \\
\hline SHS $150 \times 150 \times 6$ & $\mathrm{~S} 355 \mathrm{~J} 2 \mathrm{H}$ & 150.31 & 150.74 & 5.73 & 5.73 & 5.71 & 8.91 & 8.16 \\
\hline RHS $200 \times 100 \times 5$ & $\mathrm{~S} 355 \mathrm{~J} 2 \mathrm{H}$ & 200.01 & 100.19 & 4.62 & 4.60 & 4.65 & 3.56 & 3.56 \\
\hline RHS $150 \times 100 \times 6$ & $\mathrm{~S} 355 \mathrm{~J} 2 \mathrm{H}$ & 149.96 & 100.15 & 5.74 & 5.71 & 5.69 & 4.16 & 4.45 \\
\hline SHS $200 \times 200 \times 6$ & $\mathrm{~S} 355 \mathrm{~J} 2 \mathrm{H}$ & 202.25 & 200.48 & 5.85 & 5.87 & 5.85 & 7.42 & 6.68 \\
\hline
\end{tabular}

Table 4. Average measured dimensions of the CHS specimen

\begin{tabular}{c|l|ccc}
\hline Cross-section & $\begin{array}{l}\text { Material } \\
\text { grade }\end{array}$ & $\begin{array}{c}\mathrm{R}_{\text {external }} \\
(\mathrm{mm})\end{array}$ & $\begin{array}{c}\mathrm{R}_{\text {internal }} \\
(\mathrm{mm})\end{array}$ & $\begin{array}{c}\mathrm{t} \\
(\mathrm{mm})\end{array}$ \\
\hline CHS $219.1 \times 8.2$ & 1.4462 & 109 & 100 & 8.74 \\
\hline
\end{tabular}


Table 5. Summary of key material properties for the tensile flat coupons

\begin{tabular}{|c|c|c|c|c|c|c|c|c|c|}
\hline \multirow[t]{2}{*}{ Coupon reference } & \multirow{2}{*}{$\begin{array}{c}E \\
\left(\mathrm{~N} / \mathrm{mm}^{2}\right)\end{array}$} & \multirow{2}{*}{$\begin{array}{c}\sigma_{0.2} \\
\left(\mathrm{~N} / \mathrm{mm}^{2}\right)\end{array}$} & \multirow{2}{*}{$\begin{array}{c}\sigma_{1.0} \\
\left(\mathrm{~N} / \mathrm{mm}^{2}\right)\end{array}$} & \multirow{2}{*}{$\begin{array}{c}\sigma_{\mathrm{u}} \\
\left(\mathrm{N} / \mathrm{mm}^{2}\right)\end{array}$} & \multirow{2}{*}{$\begin{array}{c}\varepsilon_{\mathrm{u}} \\
(\%)\end{array}$} & \multirow{2}{*}{$\begin{array}{l}\varepsilon_{\mathrm{pl}, \mathrm{f}} \\
(\%)\end{array}$} & \multicolumn{3}{|c|}{$\mathrm{R}-\mathrm{O}$ parameters } \\
\hline & & & & & & & $\mathrm{n}$ & $\mathrm{n}_{0.2, \mathrm{u}}^{\prime}$ & $\mathrm{n}_{0.2,1.0}^{\prime}$ \\
\hline SHS $100 \times 100 \times 5-A 1$ & 195200 & 431 & 486 & 676 & 47.3 & 58.5 & 4.8 & 3.0 & 2.8 \\
\hline SHS $100 \times 100 \times 5-$ A2 & 191600 & 437 & 497 & 689 & 48.1 & 63.9 & 4.5 & 3.1 & 2.9 \\
\hline SHS $100 \times 100 \times 5-S$ & 184300 & 543 & 611 & 728 & 37.3 & 50.1 & 4.6 & 3.7 & 4.0 \\
\hline SHS $150 \times 150 \times 5-\mathrm{A} 1$ & 195700 & 298 & 346 & 640 & 52.7 & 65.6 & 6.2 & 2.8 & 2.2 \\
\hline SHS $150 \times 150 \times 5-\mathrm{A} 2$ & 190800 & 310 & 358 & 651 & 53.7 & 68.4 & 6.4 & 2.9 & 2.2 \\
\hline SHS $150 \times 150 \times 5-\mathrm{S}$ & 194100 & 528 & 612 & 728 & 26.7 & 28.9 & 4.9 & 3.2 & 4.4 \\
\hline RHS $150 \times 100 \times 6-\mathrm{A} 1$ & 194100 & 285 & 333 & 627 & 49.3 & 61.2 & 6.8 & 2.8 & 2.2 \\
\hline RHS $150 \times 100 \times 6-A 2$ & 192400 & 396 & 437 & 657 & 47.4 & 60.7 & 6.3 & 2.6 & 2.2 \\
\hline RHS $150 \times 100 \times 6-S$ & 197700 & 585 & 656 & 748 & 29.4 & 39.9 & 5.9 & 3.7 & 4.7 \\
\hline SHS $100 \times 100 \times 5-A 1$ & 185300 & 427 & 475 & 623 & 36.2 & 51.8 & 5.1 & 3.3 & 2.6 \\
\hline SHS $100 \times 100 \times 5-A 2$ & 188500 & 444 & 487 & 634 & 42.6 & 55.9 & 6.4 & 3.5 & 2.7 \\
\hline SHS $100 \times 100 \times 5-S$ & 185000 & 458 & 553 & 651 & 26.9 & 40.8 & $-^{(1)}$ & $-^{(1)}$ & $-(1)$ \\
\hline SHS $120 \times 120 \times 5-A 1$ & 193600 & 276 & 334 & 593 & 46.9 & 62.1 & 4.4 & 3.1 & 2.4 \\
\hline SHS $120 \times 120 \times 5-A 2$ & 191500 & 409 & 447 & 616 & 41.6 & 60.5 & 8.9 & 3.1 & 2.3 \\
\hline SHS $120 \times 120 \times 5-S$ & 194200 & 403 & 448 & 604 & 36.5 & 53.3 & 5.8 & 3.2 & 2.5 \\
\hline SHS $150 \times 150 \times 8-A 1$ & 195900 & 311 & 359 & 595 & 42.6 & 62.1 & 5.7 & 3.0 & 2.2 \\
\hline SHS $150 \times 150 \times 8-A 2$ & 192200 & 392 & 448 & 636 & 40.4 & 61.7 & 5.5 & 3.4 & 2.6 \\
\hline SHS $150 \times 150 \times 8-S$ & 193500 & 461 & 568 & 658 & 17.4 & 32.7 & 3.4 & 5.3 & 5.2 \\
\hline RHS $150 \times 100 \times 8-\mathrm{A} 1$ & 196000 & 291 & 339 & 592 & 47.2 & 69.3 & 6.2 & 3.1 & 2.2 \\
\hline RHS $150 \times 100 \times 8-A 2$ & 201000 & 305 & 349 & 600 & 53.9 & 70.6 & 6.2 & 3.1 & 2.2 \\
\hline RHS $150 \times 100 \times 8-S$ & 182000 & 553 & 623 & 679 & 19.9 & 43.0 & 4.2 & 5.2 & 5.5 \\
\hline SHS $50 \times 50 \times 2-\mathrm{A} 1$ & 189200 & 459 & 512 & 515 & 5.8 & 22.1 & $-^{(1)}$ & $-^{(1)}$ & $-^{(1)}$ \\
\hline SHS $50 \times 50 \times 2-A 2$ & 191000 & 473 & 504 & 515 & 8.8 & 26.4 & 6.6 & 7.6 & 7.6 \\
\hline SHS $50 \times 50 \times 2-\mathrm{S}$ & 190400 & 537 & 564 & 565 & 0.9 & 14.6 & 6.9 & 2.1 & 2.1 \\
\hline SHS $40 \times 40 \times 2-A 1$ & 192900 & 502 & $-(2)$ & $-^{(2)}$ & $-(2)$ & 16.9 & - & - & - \\
\hline SHS $40 \times 40 \times 2-\mathrm{A} 2$ & 198400 & 496 & - $(3)$ & 526 & 1.2 & 17.4 & 6.6 & 4.2 & - \\
\hline SHS $40 \times 40 \times 2-\mathrm{S}$ & 187100 & 523 & - $(3)$ & 558 & 1.2 & 8.2 & 4.8 & 4.5 & - \\
\hline SHS $30 \times 30 \times 2-A 1$ & 190500 & 506 & $-{ }^{(3)}$ & 535 & 0.9 & 12.6 & 8.0 & 2.3 & - \\
\hline SHS $30 \times 30 \times 2-A 2$ & 190100 & 507 & - $^{(3)}$ & 537 & 0.9 & 14.1 & 5.2 & 2.3 & - \\
\hline SHS $30 \times 30 \times 2-\mathrm{S}$ & 186400 & 512 & - (3) $^{(3)}$ & 569 & 0.9 & 13.1 & $-^{(1)}$ & $-(1)$ & $-^{(1)}$ \\
\hline RHS $120 \times 80 \times 3-\mathrm{A} 1$ & 193700 & 381 & 399 & 450 & 14.8 & 32.8 & 7.9 & 2.7 & 2.1 \\
\hline RHS $120 \times 80 \times 3-A 2$ & 201000 & 471 & 490 & 490 & 1.2 & 22.9 & 7.6 & 3.8 & 3.8 \\
\hline RHS $120 \times 80 \times 3-S$ & 198300 & 570 & 621 & 622 & 1.5 & 14.7 & 6.3 & 5.5 & 5.2 \\
\hline SHS $80 \times 80 \times 3-A 1$ & 191400 & 411 & 423 & 455 & 14.6 & 35.0 & 13.9 & 2.9 & 2.0 \\
\hline SHS $80 \times 80 \times 3-A 2$ & 189200 & 466 & $-(3)$ & 483 & 1.2 & 29.9 & 8.3 & 1.4 & - \\
\hline SHS $80 \times 80 \times 3-S$ & 185000 & 578 & -(3) & 603 & 0.8 & 11.6 & 9.8 & $\begin{array}{l}1.7 \\
1.2\end{array}$ & - \\
\hline SHS $150 \times 150 \times 8-A 1$ & 205400 & 512 & 567 & 711 & 25.5 & 49.0 & 5.7 & 3.5 & 2.6 \\
\hline SHS $150 \times 150 \times 8-A 2$ & 192000 & 525 & 589 & 745 & 29.8 & 54.8 & 4.9 & 3.8 & 2.9 \\
\hline SHS $150 \times 150 \times 8-\mathrm{S}$ & 191000 & 560 & 647 & 704 & 16.6 & 43.7 & 4.7 & 6.5 & 6.0 \\
\hline SHS $150 \times 150 \times 6-\mathrm{A} 1$ & 195000 & 393 & $395^{(4)}$ & 514 & 14.7 & 27.9 & 7.9 & - & - \\
\hline SHS $150 \times 150 \times 6-A 2$ & 191000 & 408 & $425^{(4)}$ & 529 & 15.8 & 31.9 & 6.9 & - & - \\
\hline SHS $150 \times 150 \times 6-\mathrm{S}$ & 210800 & 532 & 572 & 631 & 5.80 & 17.1 & 15.6 & 2.4 & 2.3 \\
\hline RHS $200 \times 100 \times 5-\mathrm{A} 1$ & 195000 & 421 & 456 & 494 & 9.6 & 23.0 & 5.8 & 3.8 & 3.2 \\
\hline RHS $200 \times 100 \times 5-A 2$ & 191300 & 436 & 465 & 503 & 11.7 & 30.7 & 8.1 & 2.4 & 2.9 \\
\hline RHS $200 \times 100 \times 5-S$ & 210800 & 624 & 655 & 664 & 3.1 & 13.7 & 9.9 & 2.0 & 1.6 \\
\hline RHS $150 \times 100 \times 6-\mathrm{A} 1$ & 196000 & 363 & 390 & 434 & 16.4 & 33.9 & 5.4 & 3.7 & 3.0 \\
\hline RHS $150 \times 100 \times 6-A 2$ & 206900 & 375 & 398 & 449 & 16.5 & 32.4 & 8.4 & 2.8 & 2.5 \\
\hline RHS $150 \times 100 \times 6-S$ & 197000 & 561 & 578 & 580 & 1.6 & 9.9 & 10.1 & 3.3 & 2.9 \\
\hline SHS $200 \times 200 \times 6-A 1$ & 208042 & 419 & 458 & 522 & 14.6 & 35.0 & 7.5 & 3.6 & 2.9 \\
\hline SHS $200 \times 200 \times 6-A 2$ & 202380 & 419 & 459 & 526 & 14.6 & 36.2 & 6.4 & 3.6 & 2.9 \\
\hline SHS $200 \times 200 \times 6-S$ & 192600 & 517 & 546 & 580 & 6.3 & 17.5 & 14.8 & 3.1 & 2.7 \\
\hline
\end{tabular}


(1) Erratic data prevented obtainment of values.

(2) Test was interrupted - values could not be obtained.

(3) Ultimate tensile stress preceded the $1.0 \%$ proof stress.

(4) $1 \%$ proof stress was in the plateau of the stress-strain curve.

Table 6. Summary of key material properties for the tensile corner coupons

\begin{tabular}{|c|c|c|c|c|c|c|c|c|c|}
\hline \multirow{2}{*}{$\begin{array}{l}\text { Coupon } \\
\text { name }\end{array}$} & \multirow{2}{*}{$\begin{array}{c}E \\
\left(\mathrm{~N} / \mathrm{mm}^{2}\right)\end{array}$} & \multirow{2}{*}{$\begin{array}{c}\sigma_{0.2} \\
\left(\mathrm{~N} / \mathrm{mm}^{2}\right)\end{array}$} & \multirow{2}{*}{$\begin{array}{c}\sigma_{1.0} \\
\left(\mathrm{~N} / \mathrm{mm}^{2}\right)\end{array}$} & \multirow{2}{*}{$\begin{array}{c}\sigma_{\mathrm{u}} \\
\left(\mathrm{N} / \mathrm{mm}^{2}\right)\end{array}$} & \multirow{2}{*}{$\begin{array}{c}\varepsilon_{\mathrm{u}} \\
(\%)\end{array}$} & \multirow{2}{*}{$\begin{array}{l}\varepsilon_{\mathrm{pl}, \mathrm{f}} \\
(\%)\end{array}$} & \multicolumn{3}{|c|}{ R-O parameters } \\
\hline & & & & & & & $\mathrm{n}$ & $\mathrm{n}_{0.2, \mathrm{u}}^{\prime}$ & $\mathrm{n}_{0.2,1.0}^{\prime}$ \\
\hline SHS $100 \times 100 \times 5-\mathrm{C} 1$ & 194500 & 620 & 784 & 817 & 23.3 & 32.1 & 4.1 & 14.0 & 20.3 \\
\hline SHS $100 \times 100 \times 5-\mathrm{C} 2$ & 189900 & 578 & 761 & 802 & 25.2 & 34.0 & 3.1 & 12.2 & 18.8 \\
\hline SHS $150 \times 150 \times 5-\mathrm{C} 1$ & 182000 & 561 & 671 & 819 & 34.5 & 47.6 & 3.8 & 3.5 & 4.8 \\
\hline SHS $150 \times 150 \times 5-\mathrm{C} 2$ & 180000 & 613 & 722 & 826 & 30.9 & 49.0 & 3.0 & 3.9 & 5.9 \\
\hline RHS $150 \times 100 \times 6-\mathrm{C} 1$ & 187500 & 587 & 645 & 808 & 38.4 & 51.1 & 8.2 & 2.9 & 3.0 \\
\hline RHS $150 \times 100 \times 6-\mathrm{C} 2$ & 192000 & 626 & 675 & 807 & 26.8 & 36.0 & 9.2 & 2.3 & 2.9 \\
\hline SHS $100 \times 100 \times 5-\mathrm{C} 1$ & 177700 & 522 & 673 & 734 & 19.9 & 39.0 & $-(1)$ & $-^{(1)}$ & $-^{(1)}$ \\
\hline SHS $100 \times 100 \times 5-\mathrm{C} 2$ & 172000 & 535 & 690 & 741 & 19.0 & 37.5 & $-(1)$ & - $^{(1)}$ & $-^{(1)}$ \\
\hline SHS $120 \times 120 \times 5-\mathrm{C} 1$ & 193600 & 493 & 603 & 688 & 29.9 & 46.8 & $-^{(1)}$ & $-^{(1)}$ & $-^{(1)}$ \\
\hline SHS $120 \times 120 \times 5-\mathrm{C} 2$ & 192200 & 559 & 599 & 686 & 25.5 & 47.9 & 10.8 & 3.5 & 3.0 \\
\hline SHS $150 \times 150 \times 8-\mathrm{C} 1$ & 193000 & 615 & 686 & 754 & 22.4 & 44.6 & 5.3 & 5.0 & 5.0 \\
\hline SHS $150 \times 150 \times 8-\mathrm{C} 2$ & 196200 & 592 & 653 & 746 & 25.4 & 44.9 & 5.9 & 4.0 & 3.7 \\
\hline RHS $150 \times 100 \times 8-\mathrm{C} 1$ & 206900 & 560 & 615 & 734 & 29.9 & 52.1 & 5.4 & 3.5 & 3.1 \\
\hline RHS $150 \times 100 \times 8-\mathrm{C} 2$ & 194500 & 558 & 629 & 716 & 26.5 & 49.4 & 4.2 & 4.6 & 4.6 \\
\hline RHS $120 \times 80 \times 3-\mathrm{C} 1$ & 192800 & 520 & $-(2)$ & $-(3)$ & - & - & 6.1 & - & - \\
\hline RHS $120 \times 80 \times 3-\mathrm{C} 2$ & 209400 & 515 & - $^{(2)}$ & $-^{(3)}$ & - & - & 4.9 & - & - \\
\hline SHS $80 \times 80 \times 3-\mathrm{C} 1$ & 211300 & 536 & $-(2)$ & $-(3)$ & - & - & 16.7 & - & - \\
\hline SHS $80 \times 80 \times 3-\mathrm{C} 2$ & 207700 & 524 & - $^{(2)}$ & $-^{(3)}$ & - & - & 4.7 & - & - \\
\hline SHS $150 \times 150 \times 8-\mathrm{C} 1$ & 209500 & 913 & 975 & 982 & 2.3 & 11.4 & 11.2 & 3.5 & 4.8 \\
\hline SHS $150 \times 150 \times 8-C 2$ & 204000 & 748 & 837 & 858 & 4.2 & 30.2 & 6.5 & 5.2 & 7.4 \\
\hline CHS $219.1 \times 8.2-\mathrm{C} 1$ & 191200 & 544 & 594 & 744 & 20.5 & 44.1 & 6.6 & 3.0 & 2.3 \\
\hline CHS $219.1 \times 8.2-\mathrm{C} 2$ & 189400 & 551 & 617 & 768 & 20.7 & 40.3 & 6.4 & 3.5 & 2.7 \\
\hline SHS $150 \times 150 \times 6-\mathrm{C} 1$ & 197300 & 602 & 644 & 649 & 2.6 & 15.4 & 9.9 & 4.7 & 9.6 \\
\hline SHS $150 \times 150 \times 6-\mathrm{C} 2$ & 196300 & 608 & - (4) & 639 & 1.2 & 10.8 & 10.1 & 3.2 & - \\
\hline RHS $200 \times 100 \times 5-\mathrm{C} 1$ & 180500 & 531 & $-^{(2)}$ & $-(3)$ & - & - & 4.2 & - & - \\
\hline RHS $200 \times 100 \times 5-\mathrm{C} 2$ & 200300 & 540 & $-^{(2)}$ & $-(3)$ & - & - & 5.3 & - & - \\
\hline RHS $150 \times 100 \times 6-\mathrm{C} 1$ & 201500 & 545 & - ${ }^{(4)}$ & 565 & 0.9 & 13.4 & 10.8 & 1.6 & - \\
\hline RHS $150 \times 100 \times 6-\mathrm{C} 2$ & 210000 & 528 & -(4) & 542 & 0.7 & 12.7 & 8.8 & 1.1 & - \\
\hline SHS $200 \times 200 \times 6-\mathrm{C} 1$ & 220000 & 584 & - $^{(4)}$ & 615 & 0.9 & 12.1 & 8.9 & 1.5 & - \\
\hline SHS $200 \times 200 \times 6-\mathrm{C} 2$ & 197300 & 599 & 631 & 633 & 1.4 & 13.1 & 11.3 & 3.4 & 4.1 \\
\hline
\end{tabular}

Note:

(1) Erratic data prevented obtainment of values.

(2) Coupon failed before $1.0 \%$ strain was reached.

(3) Coupon failed in the tensile machine jaws.

(4) Ultimate tensile stress preceded the $1.0 \%$ proof stress. 
Table 7. Full section tensile test results

\begin{tabular}{|c|c|c|c|c|c|}
\hline Cross-section & $\begin{array}{c}E \\
\left(\mathrm{~N} / \mathrm{mm}^{2}\right) \\
\end{array}$ & $\begin{array}{c}\sigma_{0.2} \\
\left(\mathrm{~N} / \mathrm{mm}^{2}\right)\end{array}$ & $\begin{array}{c}\sigma_{\mathrm{u}} \\
\left(\mathrm{N} / \mathrm{mm}^{2}\right)\end{array}$ & $\begin{array}{c}\varepsilon_{\mathrm{u}} \\
(\%)\end{array}$ & $\begin{array}{l}\sigma_{0.2, \text { corner }} \\
\left(\mathrm{N} / \mathrm{mm}^{2}\right) \\
\end{array}$ \\
\hline SHS $50 \times 50 \times 2-1$ & 195000 & 492 & 558 & 1.21 & \multirow{2}{*}{624} \\
\hline SHS $50 \times 50 \times 2-2$ & 202800 & 508 & 558 & 1.13 & \\
\hline SHS $40 \times 40 \times 2-1$ & 193000 & 504 & 575 & 1.21 & \multirow{2}{*}{548} \\
\hline SHS $40 \times 40 \times 2-2$ & 201285 & 516 & 577 & 1.13 & \\
\hline SHS $30 \times 30 \times 2-1$ & 199780 & 518 & 572 & 1.14 & \multirow{2}{*}{564} \\
\hline SHS $30 \times 30 \times 2-2$ & 198028 & 514 & 574 & 1.04 & \\
\hline
\end{tabular}

Table 8. Compound Ramberg-Osgood parameters obtained from coupon tests on cold-formed stainless steel sections

\begin{tabular}{l|l|c|ccc}
\hline Type & Grade & $\mathrm{T} / \mathrm{C}$ & $\mathrm{n}$ & $\mathrm{n}_{0.2, \mathrm{u}}^{\prime}$ & $\mathrm{n}_{0.2,1.0}^{\prime}$ \\
\hline \multirow{4}{*}{ Austenitic } & 1.4301 & $\mathrm{~T}$ & 5.6 & 3.0 & 4.1 \\
& & $\mathrm{C}$ & 4.5 & - & 3.5 \\
& 1.4571 & $\mathrm{~T}$ & 6.9 & 3.3 & 2.6 \\
& 1.4404 & $\mathrm{~T}$ & 5.2 & 4.0 & 3.6 \\
\hline \multirow{3}{*}{ Ferritic } & \multirow{2}{*}{1.4003} & $\mathrm{~T}$ & 8.4 & 2.9 & - \\
& & $\mathrm{C}$ & 6.1 & - & 3.0 \\
& \multirow{2}{*}{1.4509} & $\mathrm{~T}$ & 6.7 & 3.8 & - \\
\hline Duplex & 1.4462 & $\mathrm{C}$ & 6.3 & - & 3.1 \\
\hline Lean duplex & 1.4162 & $\mathrm{~T}$ & 6.5 & 3.3 & 2.5 \\
\hline & & & 7.3 & 4.0 & 5.7 \\
\hline
\end{tabular}

Table 9. Codified $\mathrm{n}$ parameters for transverse tension $(\mathrm{T})$ and compression (C)

\begin{tabular}{l|c|c|cc|cc}
\hline \multirow{2}{*}{ Type } & \multirow{2}{*}{ Grade } & EN 1993-1-4 [3] & \multicolumn{2}{c|}{ AS/NZS 4673 [1] } & \multicolumn{2}{c}{ SEI/ASCE-8 [2] } \\
\cline { 3 - 7 } & & Annealed/Cold-formed & \multicolumn{2}{c}{ Cold-formed } & \multicolumn{2}{c}{ Annealed/Cold-formed } \\
\cline { 3 - 7 } & & T/C & \multicolumn{2}{c}{ T } & C & \multicolumn{2}{c}{ T } \\
\hline \multirow{3}{*}{ Austenitic } & 1.4301 & 8.0 & 5.5 & 7.0 & 7.8 & 8.6 \\
& 1.4571 & 9.0 & - & - & - & - \\
& 1.4404 & 9.0 & 5.5 & 7.0 & - & - \\
\hline \multirow{2}{*}{ Ferritic } & 1.4003 & 11.0 & 11.5 & 11.5 & - & - \\
& 1.4509 & - & 5.0 & 5.5 & - & - \\
\hline Duplex & 1.4462 & 5.0 & - & - & - & - \\
\hline Lean duplex & 1.4162 & - & & & & - \\
\hline
\end{tabular}

Table 10. Codified n parameters for longitudinal tension $(\mathrm{T})$ and compression (C)

\begin{tabular}{|c|c|c|c|c|c|c|}
\hline \multirow{3}{*}{ Type } & \multirow{3}{*}{ Grade } & EN 1993-1-4 [3] & \multirow{2}{*}{\multicolumn{2}{|c|}{$\begin{array}{c}\text { AS-NZS } 4673[1] \\
\text { Cold-formed }\end{array}$}} & \multicolumn{2}{|c|}{ SEI/ASCE-8 [2] } \\
\hline & & Annealed/Cold-formed & & & Annea & formed \\
\hline & & $\mathrm{T} / \mathrm{C}$ & $\mathrm{T}$ & $\mathrm{C}$ & $\mathrm{T}$ & $\mathrm{C}$ \\
\hline \multirow[t]{3}{*}{ Austenitic } & 1.4301 & 6.0 & 7.5 & 4.0 & 8.3 & 4.1 \\
\hline & 1.4571 & 7.0 & - & - & - & - \\
\hline & 1.4404 & 7.0 & 7.5 & 4.0 & - & - \\
\hline \multirow[t]{2}{*}{ Ferritic } & 1.4003 & 7.0 & 9.0 & 7.5 & - & - \\
\hline & 1.4509 & - & - & - & - & - \\
\hline Duplex & 1.4462 & 5.0 & 5.5 & 5.0 & - & - \\
\hline Lean duplex & 1.4162 & - & - & - & - & - \\
\hline
\end{tabular}


Table 11. Summary of the recommended and codified $\mathrm{n}$ values for cold-formed stainless steel sections

\begin{tabular}{|c|c|c|c|c|c|c|c|}
\hline Type & Grade & $\mathrm{T} / \mathrm{C}$ & Table 8 & $\begin{array}{c}\text { Mean tensile } \\
\text { values }\end{array}$ & $\begin{array}{c}\text { EN 1993-1-4 } \\
{[3]}\end{array}$ & $\begin{array}{c}\text { AS/NZS } 4673 \\
{[1]}\end{array}$ & $\begin{array}{c}\text { SEI/ASCE-8 } \\
{[2]}\end{array}$ \\
\hline \multirow{4}{*}{ Austenitic } & & $\mathrm{T}$ & 5.6 & \multirow{4}{*}{5.6} & 6.0 & 7.5 & 8.3 \\
\hline & 1.4301 & $\mathrm{C}$ & 4.5 & & 6.0 & 4.0 & 4.1 \\
\hline & 1.4571 & $\mathrm{~T}$ & 6.9 & & 7.0 & - & - \\
\hline & 1.4404 & $\mathrm{~T}$ & 5.2 & & 7.0 & 7.5 & - \\
\hline \multirow{4}{*}{ Ferritic } & & $\mathrm{T}$ & 8.4 & \multirow{4}{*}{7.9} & 7.0 & 9.0 & - \\
\hline & & $\mathrm{C}$ & 6.1 & & 7.0 & 7.5 & - \\
\hline & \multirow{2}{*}{1.4509} & $\mathrm{~T}$ & 6.7 & & - & - & - \\
\hline & & $\mathrm{C}$ & 6.3 & & - & - & - \\
\hline Duplex & 1.4462 & $\mathrm{~T}$ & 6.5 & \multirow{2}{*}{7.2} & 5.0 & 5.5 & - \\
\hline Lean duplex & 1.4162 & $\mathrm{~T}$ & 7.3 & & - & - & - \\
\hline
\end{tabular}

Table 12. Summary of the recommended and codified Young's modulus values for stainless steel material

\begin{tabular}{l|c|c|c|c|c}
\hline Type & Grade & This study & $\begin{array}{c}\text { EN 1993-1-4 } \\
{[3]}\end{array}$ & $\begin{array}{c}\text { AS/NZS 4673 } \\
{[1]}\end{array}$ & $\begin{array}{c}\text { SEI/ASCE-8 } \\
{[2]}\end{array}$ \\
\hline \multirow{3}{*}{ Austenitic } & 1.4301 & 192000 & 200000 & 195000 & 193000 \\
& 1.4571 & 191000 & 200000 & - & - \\
& 1.4404 & 195000 & 200000 & 195000 & - \\
\hline \multirow{2}{*}{ Ferritic } & 1.4003 & 199000 & 220000 & 195000 & - \\
& 1.4509 & 190000 & 220000 & - & - \\
\hline Duplex & 1.4462 & 190000 & 200000 & 200000 & - \\
\hline Lean duplex & 1.4162 & 205000 & - & - & - \\
\hline
\end{tabular}

